\title{
Long-term study of behaviors of two cohabiting sea urchin species, Mesocentrotus nudus and Strongylocentrotus intermedius, under conditions of high food quantity and predation risk in situ
}

\author{
Peter M. Zhadan ${ }^{\text {Corresp., Equal first author, } 1 \text {, Marina A. Vaschenko }}{ }^{\text {Corresp. Equal first author, } 2}$ \\ ${ }^{1}$ Department of Geochemistry and Ecology of the Ocean, V. I. Il'ichev Pacific Oceanological Institute FEB RAS, Vladivostok, Russia \\ 2 Laboratory of Physiology, A.V. Zhirmunsky National Scientific Center of Marine Biology FEB RAS, Vladivostok, Russia \\ Corresponding Authors: Peter M. Zhadan, Marina A. Vaschenko \\ Email address: pzhadan@poi.dvo.ru, mvaschenko@mail.ru
}

Background. In the predator-sea urchin-macrophyte trophic cascade, the ecological effect of sea urchins as grazers depends both on their density and the changes in foraging activity, which are influenced by various disturbing factors. However, the complete duration of the alarm reactions of echinoids has not been studied until now. Here, we tested a hypothesis that two cohabiting sea urchins, Mesocentrotus nudus and Strongylocentrotus intermedius, which differ morphologically, might display different behavioral responses to high hydrodynamic activity and predation. Methods. We used continuous time-lapse video recording to clarify behavioral patterns of $M$. nudus and $S$. intermedius in presence of a large quantity of food (the kelp Saccharina japonica) but under different weather conditions and different types of predation threat: (1) calm weather conditions, (2) stormy weather conditions, (3) predation risk associated with the presence of several sea star species, and (4) predation risk associated with an alarm stimulus (crushed conspecifics or heterospecifics). Three separate video recording experiments (134 days in total) were conducted under field conditions. Video recording analysis was performed to determine the number of specimens of each sea urchin species in the cameras' field of view, size of sea urchins' groups, movement patterns and the duration of the alarm responses of both sea urchin species. Results. We showed that in the presence of kelp, M. nudus and S. intermedius exhibited both similar and different behavioral responses to hydrodynamics and predation threat. Under calm weather, movement patterns of both echinoids were similar but $M$. nudus exhibited the higher locomotion speed and distance travelled. Furthermore, S. intermedius but not $M$. nudus tended to group near the food substrate. The stormy weather caused a sharp decrease in movement activity followed by escape response in both echinoids. Six starfish species failed to predate on healthy sea urchins of either species, and only a few attacks on ailing PeerJ reviewing PDF | (2019:05:38071:2:0:NEW 17 Oct 2019) 
$S$. intermedius specimens were successful. The alarm response of $S$. intermedius lasted approximately $90 \mathrm{~h}$ and $20 \mathrm{~h}$ for starfish attacks on ailing conspecifics and for simulated attacks (crushed conspecifics or heterospecifics), respectively, and involved several

phases: (1) flight response, (2) grouping close to the food, (3) leaving the food, and (4) return to the food. Phase 3 was the more pronounced in a case of starfish attack. M. nudus only responded to crushed conspecifics and exhibited no grouping behavior but displayed fast escape (during $4 \mathrm{~h}$ ) and prolonged (up to 19 days) avoidance of the food source. This outcome is the longest alarm response reported for sea urchins. Discussion. The most interesting finding is that two cohabiting sea urchin species, M. nudus and S. intermedius, display different alarm responses to predation threat. Both alarm responses are interpreted as defensive adaptations against visual predators. 
1 Long-term study of behaviors of two cohabiting sea urchin species, Mesocentrotus nudus

2 and Strongylocentrotus intermedius, under conditions of high food quantity and predation

3 risk in situ

4

5 Peter M. Zhadan ${ }^{1}$ and Marina A. Vaschenko ${ }^{2}$

$6{ }^{1}$ Department of Geochemistry and Ecology of the Ocean, V. I. Il'ichev Pacific Oceanological

7 Institute FEB RAS, Vladivostok, Russia

8 22Laboratory of Physiology, A.V. Zhirmunsky National Scientific Center of Marine Biology FEB

9 RAS, Vladivostok, Russia

10 Corresponding Authors: Peter M. Zhadan, Marina A. Vaschenko

11 Email address: pzhadan@poi.dvo.ru,mvaschenko@mail.ru

ABSTRACT

14 Background. In the predator-sea urchin-macrophyte trophic cascade, the ecological effect of sea urchins as grazers depends both on their density and the changes in foraging activity, which are influenced by various disturbing factors. However, the complete duration of the alarm reactions of echinoids has not been studied until now. Here, we tested a hypothesis that two cohabiting sea urchins, Mesocentrotus nudus and Strongylocentrotus intermedius, which differ morphologically, might display different behavioral responses to high hydrodynamic activity and predation. Methods. We used continuous time-lapse video recording to clarify behavioral patterns of $M$. nudus and $S$. intermedius in presence of a large quantity of food (the kelp Saccharina japonica) but under different weather conditions and different types of predation threat: (1) calm weather conditions, (2) stormy weather conditions, (3) predation risk associated with the presence of several sea star species, and (4) predation risk associated with an alarm stimulus (crushed conspecifics or heterospecifics). Three separate video recording experiments (134 days in total) were conducted under field conditions. Video recording analysis was performed to determine the number of specimens of each sea urchin species in the cameras' field of view, size of sea urchins' groups, movement patterns and the duration of the alarm responses of both sea urchin species. Results. We showed that in the presence of kelp, M. nudus and $S$. 
30

31

32

33

34

35

36

37

38

39

40

41

42

43

44

45

46

47

48

49

50

51

52

53

54

55

56

57

58

59

60

intermedius exhibited both similar and different behavioral responses to hydrodynamics and predation threat. Under calm weather, movement patterns of both echinoids were similar but $M$. nudus exhibited the higher locomotion speed and distance travelled. Furthermore, S. intermedius but not $M$. nudus tended to group near the food substrate. The stormy weather caused a sharp decrease in movement activity followed by escape response in both echinoids. Six starfish species failed to predate on healthy sea urchins of either species, and only a few attacks on ailing $S$. intermedius specimens were successful. The alarm response of $S$. intermedius lasted approximately $90 \mathrm{~h}$ and $20 \mathrm{~h}$ for starfish attacks on ailing conspecifics and for simulated attacks (crushed conspecifics or heterospecifics), respectively, and involved several phases: (1) flight response, (2) grouping close to the food, (3) leaving the food, and (4) return to the food. Phase 3 was the more pronounced in a case of starfish attack. $M$. nudus only responded to crushed conspecifics and exhibited no grouping behavior but displayed fast escape (during $4 \mathrm{~h}$ ) and prolonged (up to 19 days) avoidance of the food source. This outcome is the longest alarm response reported for sea urchins. Discussion. The most interesting finding is that two cohabiting sea urchin species, $M$. nudus and $S$. intermedius, display different alarm responses to predation threat. Both alarm responses are interpreted as defensive adaptations against visual predators.

\section{Subjects Animal behavior, Ecology, Marine Biology, Zoology}

Keywords Predator-prey interactions, Sea urchin behavior, Chemical alarm cues, Alarm response duration, Grouping behavior, Escape response, Defensive adaptation

\section{INTRODUCTION}

The need to forage and the need to avoid predation are considered as the most important evolutionary forces in the selection of morphological and behavioral characteristics of animals (Lima, 1998; Lima \& Dill, 1990). Sea urchins (class Echinoidea), which have a long evolutionary history and a worldwide distribution, have developed a number of defense mechanisms against predators promoting survival and reproduction. Possessing a locomotion speed that is significantly inferior to that of many potential predators, sea urchins have a hard, internal calcium carbonate skeleton (test) covered by spines. Some species are additionally protected by pedicellaria with poison glands (Jensen, 1966; Cannone, 1970). Sea urchins exhibit mostly nocturnal activity for both the movement/migration (Crook et al., 2000; Dance, 1987; 
61 Hasegawa, 2014; Hereu et al., 2005) and spawning (Zhadan et al., 2018), appearing to be an 62 adaptation for enemy avoidance (Fricke, 1973).

63

64 65

66

67

68

69 70

71

72

73

74 75 76

77 78 79 80

81

82 83

Sea urchins lack image-forming eyes (Ullrich-Lüter et al., 2011); therefore, chemical senses are an essential source of information on predation risk. The emergence of chemical cues (substances emitted by predators and/or physically damaged con- or heterospecific prey) can cause various behavioral reactions in sea urchins: 'cryptic behavior', i.e. hiding in a crack or hole (Fricke, 1973; Kintzing \& Butler, 2014a; Spyksma et al., 2017); 'associative behavior', i.e. aggregation into dense groups (Bernstein et al., 1983; Hagen et al., 2002; Kintzing \& Butler, 2014a), and 'dispersion behavior', i.e. escape (Hagen et al., 2002; Urriago et al., 2011; Vadas \& Elner, 2003). For some species, it has been shown that the emergence of a chemical signal from predator presence was associated with a decrease in the intensity of feeding (the so-called 'fear effect') (Freeman, 2006; Kintzing \& Butler, 2014b; Matassa, 2010; Spyksma et al., 2017). The changes in behavior, including a decrease in foraging activity, were more pronounced in young individuals (Clemente et al., 2013; Freeman, 2006), and these behaviors may not occur in large well-armed adults (Parker \& Shulman, 1986; Wirtz \& Duarte, 2012).

Being consumers of macrophytes, sea urchins severely affect the structure of coastal benthic communities (see for review Estes \& Duggins, 1995; Mann, 1982; Steneck, 2013). There is growing evidence that in the predator-prey-plant trophic cascade, the ecological effect can be not only prey density-mediated (i.e., associated with the direct influence of predators on prey number) but also prey behavior-mediated (i.e., associated with inhibition of prey foraging activity by predators) (Abrams, 1995; Dill et al., 2003; Pearson, 2010; Schmitz et al., 2004; Trussell et al., 2006; Werner \& Peacor, 2003), prompting the suggestion that the grazing effect of sea urchins on macrophytes' abundance may depend on the duration of their alarm response. However, the complete duration of the alarm responses of sea urchin species to waterborne chemical signals emitted either from other prey (conspecific or non-conspecific), the predator itself, or both has remained unknown until now. Most studies of sea urchins' responses to chemical alarm signals have been conducted under laboratory conditions (Chivers \& Smith, 1998; Hagen et al., 2002; Kintzing \& Butler, 2014a, 2014b; Manzur \& Navarrete, 2011; Matassa, 2010; Spyksma et al., 2017), and field experiments conducted under conditions of calm water and under unidirectional water flows (Parker \& Shulman, 1986; Snyder \& Snyder, 1970; Vadas \& Elner, 2003; Wirtz \& Duarte, 2012; but see Manzur \& Navarrete, 2011; Urriago et al., 
92 2011). All these studies have focused on the initial stage of sea urchins' alarm response, whereas

93 the entire sequence of behavioral events in sea urchins in their natural habitat, starting from the 94 onset of the alarm reaction to its complete extinction, has not been investigated.

95 The present study was undertaken to identify the temporal and spatial parameters of the 96 complete alarm reactions in two species of sea urchins, Strongylocentrotus intermedius (A. 97 Agassiz, 1864) and Mesocentrotus nudus (A. Agassiz, 1864) (= Strongylocentrotus nudus) under 98 conditions of food abundance using continuous time-lapse video recording (during 1.5-2 mo) of 99 animal behavior in the field. These echinoids are abundant in coastal environments of the 100 northwestern Pacific; however, their ranges overlap only partially, in the southern part of the Sea 101 of Japan washing the coasts of Korea, Japan and the Primorye region of Russia, where the lower 102 and upper geographical boundaries of $S$. intermedius and $M$. nudus occur, respectively (see for 103 review Agatsuma, 2013a, 2013b; Kafanov \& Pavlyuchkov, 2001). In the Sea of Japan, these sea

104 urchins are common species in benthic communities inhabiting hard substrates at a depth of up to $10525 \mathrm{~m}$ (Kafanov \& Pavlyuchkov, 2001). Morphologically, S. intermedius and M. nudus differ from 106 each other in respect to the color (brownish-black in M. nudus and brownish-grey in $S$.

107 intermedius) and spine length and hardness (hard sharp spines of up to $30 \mathrm{~mm}$ in M. nudus and 108 less hard spines of up to $8 \mathrm{~mm}$ in S. intermedius). We hypothesized that these sea urchin species, 109 presumably sharing an evolutionary history but differing morphologically, might display 110 different behavioral responses to various disturbing factors such as high hydrodynamic activity 111 and predation.

112

MATERIALS AND METHODS

114 Study areas, sea urchins and video recording experimental setup

115 Field experiments were conducted in the northwestern Sea of Japan: Kievka Bay $\left(42.830^{\circ} \mathrm{N}\right.$, $\left.116133.691^{\circ} \mathrm{E}\right)$ and Alekseev Bay $\left(42.981^{\circ} \mathrm{N}, 131.730^{\circ} \mathrm{E}\right)$. Kievka Bay, with a width of $8.3 \mathrm{~km}$ and 117 a length of $3.3 \mathrm{~km}$, is typical of the southeastern coast of the Primorye region of Russia. Being 118 open to prevailing summer winds from the southeast to the southwest, the bay is characterized by 119 high wave activity. The studies here were performed at a depth of $6 \mathrm{~m}$ on relatively flat bedrock 120 surrounded by large stones. Alekseev Bay has a width of $0.8 \mathrm{~km}$ and a length of $1.3 \mathrm{~km}$, and 121 wave activity here is high only under winds from the north, a phenomenon that is quite rare in 122 summer. The studies here were performed at a depth of $2 \mathrm{~m}$ on a flat bottom covered with 
123 medium sized gravel. Within both bays, water depth is weakly influenced by tidal activity: an

124 irregular semidiurnal tide has a maximum amplitude of approximately $50 \mathrm{~cm}$ (Zhadan et al., 125 2018).

126 In both bays, the density of S. intermedius and M. nudus in the areas adjacent to the 127 experimental installations was 1 to 2 ind. $\mathrm{m}^{-2}$ (Zhadan et al., 2018). In addition, to balance the 128 density of the species in the study areas, approximately 300 specimens of $S$. intermedius were 129 collected in the bays in a radius of 100-200 $\mathrm{m}$ from the experimental installations and placed at a 130 distance of 10-20 m from them. The video observation of sea urchins' behaviors was performed 131 with TLC200 Pro (Brinno Incorporated) time-lapse video cameras mounted on steel stanchions approximately $1 \mathrm{~m}$ above the bottom. Time-lapse videos were taken in $1 \mathrm{~min}$ intervals at a resolution of $1280 \times 720$ pixels. The cameras were installed in such a way that the size of the field of view was approximately $1.5 \times 1.0 \mathrm{~m}$. During the night, the cameras' fields of view were illuminated by LED lamps $(1 \mathrm{~W})$ which were synchronized with the cameras by flash LED indicator. The illumination duration was $1 \mathrm{~s}$.

To attract sea urchins in the field of view of video cameras, flat mesh containers filled with the kelp Saccharina japonica (Laminariales, Phaeophyta; hereafter simply laminaria) were used. It is known that laminaria stimulates foraging activity of M. nudus and S. intermedius (Machiguchi, 1987; Machiguchi et al., 1994). The containers, each composed of 2 steel frames and mesh stretched on them, $1.1 \times 0.75 \times 0.01 \mathrm{~m}$ in size, were filled with laminaria and placed in

142 the cameras' field of view. Each container (hereafter feeder) contained approximately $30 \mathrm{~kg}$ of 143 the kelp. Sea urchins of both species themselves found the feeders and populated them within 21443 days. All sea urchins that were in the cameras' field of view on all the feeders were taken into account for further video analysis. The steel frames of the containers were pressed down by stones with a diameter of $20-40 \mathrm{~cm}$ to protect against wave activity.

The indicator of the onset of sea urchins' alarm response was the escape or redistribution of sea urchins in the field of view of the cameras, and the indicator of the end of the alarm reaction was the return of sea urchins to their original spatial distribution pattern. Such a design of the experiments allowed us to clarify (1) the features of sea urchins' behavior in the presence of abundant palatable food and under different weather conditions, (2) the frequency of predator attacks under natural conditions, and (3) the temporal patterns of the complete behavioral response of sea urchins to a natural predator attack and simulated predator attack (crushed 
154 conspecifics or heterospecifics) in sea urchin species with different morphological

155 characteristics.

156

\section{Video recording analysis}

158 The recorded videos were viewed frame by frame. We counted the numbers of specimens of 159 each sea urchin species in the each camera field of view both in the absence and in the presence

160 of disturbing factors. To access the grouping behavior of the sea urchins, we calculated the mean 161 group size as the ratio of the total number of individuals in the cameras' field of view to the 162 number of associations (Hagen \& Mann, 1994). Following Vadas et al. (1986), we distinguished

163 between sea urchin associations and aggregations. Each group of sea urchins in two-dimensional 164 165 groupings, including individuals suspected of being in tactile contact (there was no visible space between them) and single individuals, was considered a separate association.

166

To determine the mean group size for both sea urchin species, the video frames were randomly selected over the periods of calm weather. Only the video frames showing not more than 30 specimens (43 frames for each species) were chosen for the mean group size calculation in order to avoid crowding effects when sea urchins might be in tactile contact due to their high density on the feeders. Under such a limitation, no groups of 3 or more sea urchins in cohesive three-dimensional groupings (aggregations, according to Vadas et al., 1986) were observed in our study.

Sea urchins' movement was analyzed using the free software, 'Tracker', for video analysis (www. open sourcephysics.org/items/detail.cfm?ID=7365). The cell size $(2 \times 2 \mathrm{~cm})$ of the feeder mesh was used as a scale. We tracked and measured sea urchin displacement with an interval of 1 min. Following Lauzon-Guay et al. (2006), we defined a step as the distance between two successive positions of the sea urchin (1 min apart), a stop as an interval when sea urchin remains stationary during at least $1 \mathrm{~min}$ ( 2 successive frames) and a move as the distance between two successive stops which can be composed of one or more steps. The mean locomotion speed was calculated as total distance passed divided by total time.

\section{Long-term video recording of sea urchins' behavior}


185 2016). In these experiments, 4 cameras were used, and 4 feeders were arranged in pairs in such a 186 way that the direction of the tidal currents coincided with the direction of the long sides of the 187 feeders. The distances between the long sides of the feeders were $0.4 \mathrm{~m}$, and the distance 188 between the pairs of the feeders was $2 \mathrm{~m}$. The feeders were replaced every 15-20 days (see Fig. 189 1) when approximately $80 \%$ of laminaria was consumed by sea urchins. Sea urchins were 190 carefully transferred from the old feeders to the feeders with fresh laminaria. It took 191 approximately 5 min to change one feeder.

192 We tested for behavioral differences between M. nudus and S. intermedius in presence of 193 a large quantity of palatable food but under different weather conditions and different types of 194 predation threat: (1) under calm weather conditions, (2) under stormy weather conditions, (3) 195 196 197 198 199 under predation risk associated with the presence of several sea star species, and (4) under predation risk associated with simulated predator attack (crushed individuals of $M$. nudus). The numbers of specimens of each sea urchin species were counted per each $6 \mathrm{~h}$ of observations throughout all 3 long-term experiments, both in the absence and in the presence of disturbing factors (see Table S1 for original data).

200

The stormy periods were determined by several signs which are clearly visible on video

201

202

203

204 205

206

207

208

209

210

211

212

213

214 215

recordings: (1) the oscillation of the feeder surface and (2) the increase in suspended particles movement and water turbidity. In addition, an increase in wave height during storm was recorded by the depth sensor of a multi-parameter RBRXRX-620 datalogger (Sea and Land Technologies Pte, Singapore) which measured the sea level every 10 min (see for example Fig. S1).

We compared movement parameters (the number and length of the steps and moves, the entire displacement, the number and duration of the stops, the entire stationary period and mean speed) of both sea urchin species under calm and stormy weather conditions. For this purpose, the distances traversed by randomly selected 10 sea urchins of each species during 240 min before the storm and in the beginning of the storm (Fig. S1) were tracked and measured with an interval of 1 min (see Tables S2 and S3 for raw data). Further tracking showed that a half of observable sea urchins left the cameras' field of view during approximately $10 \mathrm{~h}$ after the beginning of measurements. Locomotion speed during escape was calculated as total distance passed during the period from the beginning of active movement of the sea urchin to its disappearance from the field of view divided by the total time of escape (see Tables S2 and S3 for raw data).

PeerJ reviewing PDF | (2019:05:38071:2:0:NEW 17 Oct 2019) 
Predation risk was associated with several species of sea stars that were present

217 simultaneously with sea urchins on the feeders or with simulation of predation attack (crushed

218 individuals of $M$. nudus). To determine behavioral responses of S. intermedius to starfish attacks

219 on the conspecifics which took place on September 5 and 21, 2015 (see Table S1), we measured

220 the distances of 13 sea urchins closest to the site of the attack (i.e., their entire displacement)

221 during approximately $100 \mathrm{~h}$ after the beginning of the attack with the intervals from $2 \mathrm{~h}$ to $4-16$

$222 \mathrm{~h}$. For these periods, the total numbers of $S$. intermedius specimens as well as the individuals of 2 223 starfish species, P. pectinifera and L. fusca, which were in contact with the prey, were counted.

224 Our pilot experiments showed that M. nudus rapidly left the area of the bottom where 225 conspecifics were crushed and avoided it for a long time. There was no similar reaction to 226 crushed $S$. intermedius specimens. Furthermore, S. intermedius exhibited no visible responses 227 both to crushed conspecifics and heterospecifics. Therefore, we focused on the study of the 228 phenomenon of $M$. nudus response to crushed conspecifics. We compared how quickly $M$. nudus 229 populated the feeders in the presence and in the absence of crushed conspecifics. In the first case, $23010 \mathrm{M}$. nudus specimens with test diameters of 50-60 mm were crushed in the middle between the 231 pairs of the feeders when $M$. nudus were present on them (5 experiments in total; we did not 232 include the data of 1 experiment into statistical analysis because it might be influenced by the 233 experiment on storm imitation conducted 3 days earlier). In the second case, all M. nudus 234 specimens were removed from the cameras' fields of view and transferred to a distance of 235 approximately $10 \mathrm{~m}$ from the feeders (7 experiments in total; we did not include the data of 3 236 experiments into statistical analysis because they might be influenced by the previous or next 237 storm). In both cases, we estimated the temporal dynamics of the numbers of sea urchins (with 238 time intervals of $1 \mathrm{~h}$ and $6 \mathrm{~h}$ in the first and second cases, respectively).To test our assumption 239 that the storm contributes to the return of sea urchins $M$. nudus to the feeders, two experiments 240 mimicking stormy conditions were conducted several days (6 and 12 in 2014 and 2016, 241 respectively, see Table S1) after $M$. nudus left the feeders in response to crushed conspecifics.

242 The feeders were removed, and several scuba divers actively swam in the area of the 243 experimental installation. After that, the feeders with fresh laminaria were placed in their original 244 place. These procedures took 30-40 min. The average sea urchin numbers for 1 day before 245 crushing and 2 days after storm imitation were determined. 


\section{Short-term video recording of sea urchins' behavior}

248 A set of experiments, each with a duration of approximately $6 \mathrm{~d}$, was conducted in Alekseev Bay

249 from July-September 2016. The experiments were designed to elucidate behavioral patterns of

250 M. nudus and S. intermedius in response to an alarm stimulus (crushed conspecifics or

251 heterospecifics). In each of these experiments, 2 video cameras and 2 feeders were used. Two

252 days after the feeder placement, when 30-40 sea urchins of both species were gathered on the

253 feeder surface, 5 specimens of $S$. intermedius or M. nudus were crushed at a distance of $20 \mathrm{~cm}$

254 from the feeder's short side. Three to four days after simulation of the predation threat, all the

255 sea urchins were removed from the cameras' field of view, and the experiment was repeated on

256 the other feeder with fresh laminaria and with sea urchins not previously used. In total, 4

257 experiments of this kind were carried out with each of sea urchin species used as simulated prey.

258 During $22 \mathrm{~h}$ before and $55 \mathrm{~h}$ after the treatment, we estimated the numbers of sea urchins as well

259 as the temporal dynamics of the mean group size (with time intervals from 1 to $4 \mathrm{~h}$ ) with one

260 exception: we failed to assess the temporal dynamics of the mean group size of sea urchins $M$.

261 nudus in response to crushed conspecifics due to fast escape of $M$. nudus.

262 To determine movement patterns of sea urchins in response to crushed con- and

263 heterospecifics, we measured step length and locomotion speed before and after treatment.

264 Additionally, we measured with intervals of 6-9 min the distances of 10 sea urchins closest to

265 the site where simulated attack was performed. The exception was a case with response of $M$.

266 nudus to crushed conspecifics because sea urchins rapidly left the cameras' field of view.

267 Duration of sea urchin tracking was from 200 to 1200 min due to the species specific response of 268 sea urchins to the alarm signal.

269

\section{Statistical analysis}

271 To analyze the species-specific and treatment-specific differences in M. nudus and S. intermedius

272 behavior, the data sets on the numbers of sea urchins, mean group sizes as well as sea urchins'

273 movement parameters were formed and tested for normal distribution (D'Agostino and Pearson

274 omnibus normality test, $P<0.05)$. Normally distributed data were further analyzed by parametric

275 tests (unpaired $t$-test, 1-way ANOVA). In a case of abnormally distributed data, non-parametric

276 tests were used (Mann-Whitney test, Kruskal-Wallis test followed by Dunn's multiple

277 comparisons). To analyze the temporal dynamics of the numbers of both sea urchins in the 
278 experiments on the response to crushed conspecifics or heterospecifics as well as in the 279 experiments on the repopulation the feeders by sea urchins M. nudus after their removal, linear 280 or nonlinear regression (curve fit) were used. All statistical analyses were run using GraphPad 281 Prism v. 6.0.The details regarding raw data and statistics are presented in the Supplementary 282 Materials. In all the Figures, the data relating to M. nudus is in blue color and the data relating to 283 S. intermedius is in red color.

284

\section{Procedural controls}

286 In our in situ experiments we did not use the procedural controls which are usuallyapplied in the 287 experiments with animals contained in tanks or cages, such as 'food presence - food absence', 288 'animal treatment/manipulation - imitation of animal treatment/manipulation'. First, both sea 289 urchin species exhibited clear food search behavior, and the absence of food strongly stimulated 290 them to migrate to the place where the food is present. Second, we minimized manipulations in 291 our experiments that could affect the results and conclusions. A negligible displacement of water 292 masses near a feeder associated with sea urchins' crushing as well as the swimming of the diver, 293 who served the installation, above the feeder did not cause escape reactions of both sea urchin 294 species similar to those during storm. The experiments mimicking stormy conditions were 295 conducted in the absence of the feeders. Both in long-term and short-term experiments, we used 296 short-term periods (from 1 to 3 days) just before the treatments as proper procedural controls, 297 and compared quantitative parameters (sea urchins' number and mean group size) obtained for 298 these periods with those obtained for the periods after the treatments (storms, starfish attacks or 299 crushed sea urchins).

RESULTS

\section{General characteristics of sea urchins' behavior}

303 During the recording periods in 2014, 2015 and 2016 (134 days in total), $24 \pm 25$ (mean \pm SD) of 304 M. nudus specimens and $78 \pm 42$ of $S$. intermedius specimens were in the field of view of the 305 video cameras (Fig. 1A-C, Table S1). During the periods without any treatment (storms, $M$. 306 nudus specimens removal or crushing, starfish attacks), the numbers of M. nudus and $S$.

307 intermedius were higher, $50 \pm 15$ and $85 \pm 42$, respectively. The size composition of the two 308 echinoid species was slightly different. Only large adults of $M$. nudus with a test diameter of 62.2 
$309 \pm 7.5 \mathrm{~mm}($ mean $\pm \mathrm{SD})$ were present in the cameras' field of view, whereas among the adult $S$.

310 intermedius with test diameters from 37 to $74 \mathrm{~mm}(64.4 \pm 4.3 \mathrm{~mm})$, there was a small number

311 (up to $12 \%$ ) of juveniles with test diameters of 10-15 $\mathrm{mm}$. On the surface of the feeders, both sea

312 urchin species were relatively evenly distributed in one plane and did not form aggregates (three-

313 dimensional groups); however, they formed associations (dense two-dimensional groups).

314 Grouping behavior in S. intermedius was expressed to a greater extent than in M. nudus: when

315 from 14 to 25 of individuals were present on the surface of the feeders, the mean group size of $S$.

316 intermedius was approximately 2 times higher than that of $M$. nudus $(2.27 \pm 0.4$ versus $1.12 \pm$

3170.1 , Mann-Whitney test, $\mathrm{U}=0, P<0.0001$; see Table $\mathrm{S} 4$ for raw data and statistics).

318 Both sea urchin species displayed so called 'covering behavior' but it was more

319 pronounced in $S$. intermedius than in $M$. nudus. The debris covering sea urchin aboral surfaces

320 consisted mainly of pieces of the algae such as Ulva fenestrata Ruprecht, 1840 and Desmarestia

321 viridis (O.F. Müller) J.V. Lamouroux, 1813 in June-July, and seagrass Zostera marina L. in the

322 end of September. During these periods, from 87 to $100 \%$ of $S$. intermedius individuals were

323 decorated compared to from 0 to $18 \%$ for $M$. nudus.

324

325 Behavioral responses of sea urchins to increased wave activity

326

327

328

329

330

331

332

333

334

335

336

337

338

339

During the storms, the number of sea urchins of both species in the cameras' field of view sharply decreased (Fig. 1A-C, see Table S1 for raw data). On the eve of the storm periods, there were $54 \pm 9$ (mean $\pm \mathrm{SD}$ ) of $M$. nudus specimens and $76 \pm 37$ of $S$. intermedius specimens whereas during the storms, the average numbers for both species $(26 \pm 15$ and $34 \pm 21$ for $M$. nudus and S. intermedius, respectively) were significantly lower (Fig. 2, see Tables S5, S6 for raw data and statistics). Approximately one day after the storm, sea urchins of both species restored their numbers on the feeders (Fig. 1A-C, Fig. 2, Tables S5, S6).

Both sea urchin species exhibited similar patterns of movement under conditions of calm weather. The average numbers of moves and stops were not significantly different between species, however, the moves of $S$. intermedius were shorter and consisted of higher number of shorter steps whereas the locomotion speed and entire distance travelled were significantly higher in M. nudus (Tables 1 and 2, see also Table S7 for interspecies comparison).

Both sea urchin species responded to increased wave activity by a sharp decrease in the number of steps, length of one move and entire distance travelled (Tables 1 and 2, see also Table

PeerJ reviewing PDF | (2019:05:38071:2:0:NEW 17 Oct 2019) 
340 S7 for interspecies comparison). At the same time, the duration of one stop increased

341 approximately 3 and 4 times in $S$. intermedius and $M$. nudus, respectively, and the average

342 proportions of time sea urchins spent stationary were 76 and 91\%, respectively, against 33 and

$34354 \%$ under calm weather. The average locomotion speeds during storm conditions were as low

344 as 0.07 and $0.03 \mathrm{~cm} \mathrm{~min}^{-1}$ in $S$. intermedius and $M$. nudus, respectively. During escape, sea

345 urchin speeds sharply increased and averaged $0.82 \pm 0.19$ (range of 0-7.02) $\mathrm{cm} \mathrm{min}^{-1}$ in $S$.

346 intermedius and $1.76 \pm 0.30$ (range of $0-11.81) \mathrm{cm} \mathrm{min}^{-1}$ in $M . n u d u s$, these were, respectively,

3474.3 and 5.5 times higher than those under calm weather (see Tables S2 and S3 for raw data).

348

349 Behavioral response of S. intermedius to starfish attack

350 Over 3 periods of our studies, only three cases of the attacks of the sea stars (Patiria pectinifera

351 (Muller \& Troschel, 1842) and Lethasterias fusca Djakonov, 1931) on single individuals of $S$.

352 intermedius were recorded (5, 10 and 21 September, 2015, see Table S1) whereas no attacks of

353 predators on sea urchins $M$. nudus were observed. Judging by the presence of injuries and

354 abnormal behavior (low motor activity and body position with the oral surface upward), only

355 sick or damaged individuals of $S$. intermedius have been attacked by sea stars (Fig. S2A). It is

356 possible that the appearance of damaged S. intermedius specimens that have lost a significant

357 part of the spines was due to typhoon 'Goni', which occurred on August 27-29, 2015 in the

358 northwestern Sea of Japan.

359

On September 10, sea urchin reaction to a predator attack could not be traced due to low

360 visibility caused by the storm. The behaviors of sea urchins $S$. intermedius during starfish attacks

361 on September 5 and 21, 2015 were slightly different. On September 5, one S. intermedius

362 specimen was consumed by 1-5 individuals of $P$. pectinifera and 1 individual of $L$. fusca in the

363 centre of one of the 4 feeders for $45 \mathrm{~h}$ (Fig. 3A, see also Fig. S2). Within $2 \mathrm{~h}$ after the beginning

364 of the attack, most of the sea urchins left the surface of the feeder and formed several groups on

365 the tops and at the base of nearby stones (Fig. S2B). The number of sea urchins in the cameras'

366 field of view was relatively stable during the first $12 \mathrm{~h}$, and sea urchin distances from the site of

367 attack did not change much (Fig. 3A). Then, the distances began to increase sharply, and their

368 maximum coincided with maximum number of sea stars consuming an ailing specimen (Fig.

369 3A). $26 \mathrm{~h}$ after the beginning of starfish attack, the number of sea urchins in the cameras' field of

370 view began to decrease, and after $50 \mathrm{~h}$, there remained approximately $30 \%$ of sea urchins (Figs.

PeerJ reviewing PDF | (2019:05:38071:2:0:NEW 17 Oct 2019) 
$3713 \mathrm{~A}$ and S2C). The number of sea urchins on the feeder began to increase between 16 and $28 \mathrm{~h}$

372 after the starfish left the sea urchin remains, and this coincided with gradual decrease of sea

373 urchin distances from the site of attack (Fig. 3A). In general, the alarm reaction of S. intermedius

374 from the onset of the starfish attack to restoration of the initial sea urchin population on the

375 surface of the feeder (Figs. 3A and S2D) lasted for approximately $90 \mathrm{~h}$.

376 On September 21, a starfish attack occurred at the short edge of the feeder. Sea urchin

377 distances from the site of attack were almost unchanged during the first $9 \mathrm{~h}$ and then sharply

378 increased, and this coincided with maximum number of sea stars (P. pectinifera and L. fusca)

379 consuming an ailing specimen (Fig. 3B). After 24 h, no S. intermedius specimens remained

380 closer than $40 \mathrm{~cm}$ from the site of attack. They formed associations on the feeder and the nearest

381 stones. Eight hours after the beginning the attack, the number of sea urchins in the cameras' field

382 of view began to decrease, and after $55 \mathrm{~h}$, there remained approximately $50 \%$ of sea urchins.

383 Consumption of the prey by the sea stars lasted $70 \mathrm{~h}$. Restoration of sea urchin abundance and

384 distribution on the feeder began $10 \mathrm{~h}$ after the sea stars left the remains of the prey. The total 385 duration of the sea urchin alarm reaction was $88 \mathrm{~h}$ (Fig. 3B).

$386 \quad$ It should be noted that the sea stars P. pectinifera and L. fusca were constantly present on 387 the feeders. The starfish Asterias amurensis Lutken, 1871, Distolasterias nipon (Döderlein, 388 1902), Lysastrosoma anthosticta Fisher, 1992 and Aphelasterias japonica Bell, 1881 also often 389 appeared on the feeders. With a few exceptions, these starfish did not cause visible reactions in 390 healthy sea urchins. The behavior of P. pectinifera was the most aggressive. In one case, during 39128 min, $P$. pectinifera attacked an S. intermedius specimen, which lost approximately $20 \%$ of its 392 spines, but finally, it was left alone. In two cases, sea stars P. pectinifera completely crawled on 393 S. intermedius individuals in such a way that starfish mouth was located directly above the sea 394 urchin's anal orifice. After 11 and $15 \mathrm{~min}$ in the first and second cases, respectively, the sea stars 395 left the potential prey, which indicates that a healthy sea urchin can effectively resist the 396 penetration of a starfish stomach through the anus.

397

\section{Behavioral responses of M. nudus and S. intermedius to crushed M. nudus} 399 specimens

400 Four experiments conducted during long-term recordings of 2014-2016 (Fig. 1A-C, Table S1)

401 showed that after the conspecifics were crushed near the feeders, approximately $90 \%$ of $M$. 
402 nudus individuals left the cameras' field of view during $4 \mathrm{~h}$ (Fig. 4, see Table S8 for raw data 403 and statistics). During this period, a sharp increase in the average step length just after the 404 treatment was recorded (Fig. 5). There were 2 time intervals with the highest locomotion speed, 405 the first 55 min after the treatment when a half of $M$. nudus specimens left the cameras' field of 406 view, and the last 128 min when the rest of sea urchins escaped (Fig. S3A). These intervals were 407 interrupted by the relatively stable 1 hour period when sea urchins almost stopped moving (Fig. 408 5).

Nine hours after the beginning of the experiment, there were no $M$. nudus specimens on

410

411

412

413

414

415

416

417

418

419

420

421

422

423

424

425

426

427

428

429

430

431

the feeders (Fig. 4, Table S8), and then, during a much longer period (7-19 days), only single $M$. nudus individuals appeared (Fig. 1A-C). The restoration of the initial sea urchin numbers on the feeders occurred only after the next storm event.

The imitation of stormy weather also contributed to the return of $M$. nudus after sea urchins left the feeders in response to presentation of crushed conspecifics. Sea urchins were absent on the feeders during approximately 5 and 13 days in 2014 and 2016, respectively, and came back within 2 days after intensive swimming and replacement of the feeders; however, their number was lower than that before the experiments (Figs. 1A, C and S4, Table S1).

Four experiments conducted during long-term recordings of 2014-2016 (Fig. 1A-C, Table S1) demonstrated that, in the absence of crushed conspecifics, sea urchins $M$. nudus came back 2-3 days after their removal from the surfaces of the feeders (Fig. 6, see Table S9 for raw data and statistics).

Sea urchins $S$. intermedius did not leave the cameras' field of view during the experiments with presentation of crushed M. nudus specimens (Fig. 1A-C, Table S1); moreover, statistical analysis revealed small but significant increase in $S$. intermedius numbers in 3 cases when M. nudus was absent on the feeders (see Table S10 for statistics). Spatial pattern of $S$. intermedius remained almost unchanged with the exception of one case: after the $M$. nudus specimens were crushed, sea urchins $S$. intermedius avoided the surface of the feeder for $24 \mathrm{~h}$ and were among the stones opposite of the crushed M. nudus.

Behavioral responses of $M$. nudus and S. intermedius to crushed conspecifics and heterospecifics

PeerJ reviewing PDF | (2019:05:38071:2:0:NEW 17 Oct 2019) 
432 In the 6-d short-term experiments, $M$. nudus exhibited a strong avoidance reaction in response to 433 crushed conspecifics similar to that in long-term observations (Fig. S5A, see Table S11 for raw 434 data and statistics). When $S$. intermedius individuals were crushed near the feeders, behavior of 435 sea urchins $M$. nudus remained unchanged, as evidenced by the absence of significant changes in 436 such indicators as the number of sea urchins in the cameras' field of view (Fig. S5B, see Table 437 S12 for raw data and statistics) and mean group size (Fig. S5C, see Table S13 for raw data and 438 statistics). Analysis of M. nudus movement activity also revealed no differences in the average 439 step length (Fig. 7A), distance from the site of simulated attack (Fig. 7B) and locomotion speed 440 (Fig. S3C).

$441 \quad$ In response to crushed conspecifics, S. intermedius moved towards the opposite side of 442 the feeder and formed associations there. Before the experiment, the mean group size was $2.25 \pm$ 4430.75 (mean $\pm \mathrm{SD}$ for $21 \mathrm{~h}$ of observation), and this parameter was 2.5 -fold higher $(5.85 \pm 2.18$ ) 444 during the $14 \mathrm{~h}$ period after the stimulus was presented (Fig. 8A, see Table S14 for raw data and 445 statistics). The changes in the number of sea urchins in the cameras' field of view were not very 446 obvious (Fig. 9A); however, linear regression showed significant decrease in this parameter $(P<$ 4470.0001 , see Table S15 for raw data and statistics). The associations were positioned in such a 448 way that sea urchins were partly on the feeder and partly outside it. On average, approximately $44940 \%$ of the sea urchins, both grouped and alone, were located in the immediate vicinity outside 450 the feeders. Judging by the restoration of the original spatial distribution of sea urchins on the 451 feeder (the initial mean group size), the duration of the alarm reaction of $S$. intermedius was 452 approximately $18 \mathrm{~h}$ (Fig. 8A).

Analysis of $S$. intermedius movement revealed 2 time intervals of the highest activity, 454 each approximately $1.5 \mathrm{~h}$ in duration: the first when sea urchins formed associations and the 455 second when these associations dispersed (Figs. 10 and S3B, see Table S16 for raw data). 456 Between these 2 peaks of activity, there was prolonged period of approximately $16 \mathrm{~h}$, when the 457 average step length and locomotion speed were relatively low, and the distance from the site of 458 simulated attack was almost unchanged. Judging by the dynamics of the mean group size, response of $S$. intermedius to crushed 460 individuals of M. nudus was generally similar to the response to crushed conspecifics (Fig. 8B, see Table S17 for raw data and statistics). Movement analysis showed that just after the treatment, there was an increase in the average step length (Fig. 7A), distance from the site of 
463 simulated attack (Fig. 7B) and locomotion speed (Fig. S3D). A vast majority of sea urchins did 464 not leave the cameras' field of view (Fig. 9B), and linear regression showed no significant 465 decrease in this parameter ( $P=0.3485$; see Table S18 for raw data and statistics). The original 466 spatial distribution of sea urchins on the feeder was restored within approximately $20 \mathrm{~h}$ after the 467 beginning of simulated attack (Fig. 8B).

468

469

470

471

472

473

474

475

476

477

478

479

480

481

482

483

484

485

486

487

488

489

490

491

492

493

\section{DISCUSSION}

The present work is the first study analyzing long-term, around-the-clock behavior of sea urchins exposed under field conditions to both calm and stormy weather and to presentation of two competing stimuli, food and predation threat, which are assumed to be key factors influencing species survival. Due to the natural turbidity of sea water, video camera cannot register the initial stages of the sea urchin alarm reaction, namely, extension of the tube feet and movement of spines, which are manifested in the first seconds or minutes after sea urchin exposure to an alarm signal (Morishita \& Barreto, 2011; Urriago et al., 2011). At the same time, the method of continuous time-lapse video recording allowed analysis of the long-term dynamics of the spatial distributions of sea urchins under natural conditions when both stimuli were presented.

Previously, several authors applied video recording in the field to quantify sea urchins at the kelp grazing front (Lauzon-Guay \& Scheibling, 2007) and to determine sea urchin movement patterns (Dumont et al., 2007; Lauzon-Guay et al., 2006); however, they used separate time-lapse video sequences, each lasting several hours. We showed that two sea urchin species, different in morphology and living under similar conditions, exhibited distinctly different strategies for avoiding predation in terms of response duration and behavioral patterns.

\section{Sea urchin response to hydrodynamics}

In the absence of predation threat, $S$. intermedius and $M$. nudus also showed somewhat different behavioral patterns. Under calm weather, S. intermedius much more often than M. nudus exhibited the covering behavior and tended to group on the food substrate. Despite general patterns of movement (intermittent locomotion, characterized by moves interspersed with pauses) in both species, $M$. nudus spent more time stationary but moved at approximately 2 times higher speed than S. intermedius, resulting in the higher distance traversed. However, both species are highly mobile, and under conditions of calm sea and presence of food, $M$. nudus and 
494 S. intermedius would be able to move on average 4.6 and $2.7 \mathrm{~m}$ per day, respectively (calculated 495 based on the average locomotion speeds). These average distances are similar to those observed 496 for the sea urchins Strongylocentrotus droebachiensis (0.4-1.72 m; Dumont et al., 2006), 497 Toxopneustes roseus (1.65 and $2.49 \mathrm{~m}$; James, 2000), Tripneustes ventricosus (3.7 and $8.8 \mathrm{~m}$; 498 Tertschnig, 1989) and Diadema antillarum (3.7 m; Tuya et al., 2004).

499 The results of both laboratory and field experiments evidence that sea urchins are capable 500 to sense a change in hydrodynamic activity and react by changing the behavior. In our study, 501 both sea urchins responded to the stormy weather, firstly, by decreasing the movement activity 502 up to almost complete stop and secondly, by leaving the food. It is noteworthy that during escape 503 under the stormy conditions, sea urchins can move on average 4-5-fold faster than during 504 feeding under calm weather.

505 It is known that with increasing water velocity (higher than approximately $15 \mathrm{~cm} \mathrm{~s}^{-1}$ ), sea 506 urchins decrease their displacement and cease feeding both under laboratory (Kawamata, 1998;

507 Frey \& Gagnon, 2016; Cohen-Rengifo et al., 2018; Tamaki et al., 2018) and field (Lissner, 1980; 508 Dance, 1987; Siddon \& Witman, 2003; Dumont et al., 2006, 2007) conditions. Escape behavior 509 was also observed in laboratory flume experiments: at flow velocity $\leq 30 \mathrm{~cm} \mathrm{~s}^{-1}$, sea urchins 510 moved in a downstream direction whereas at $35-45 \mathrm{~cm} \mathrm{~s}^{-1}$, individuals moved in an upstream 511 direction (Morse \& Hunt, 2013; Cohen-Rengifo et al., 2018). However, escape response of sea 512 urchins to wave-induced benthic water flow in situ has been poorly documented. Dance (1987) 513 observed that during a period of turbulence lasting several hours, movement of $P$. lividus was 514 significantly oriented to the deep water with lower hydrodynamic activity. Lauzon-Guay \& 515 Scheibling (2007) found that S. droebachiensis density at the grazing front decreased when wave 516 action increased and suggested that the 'whiplash effect' of the swaying kelp prevented sea 517 urchins from climbing onto kelp plants. In our study, the kelp was packed into mesh containers 518 and formed a kind of soft substrate. We believe that sea urchins M. nudus and S. intermedius, 519 being able to sense an oscillation of the substratum and/or increasing water flow, reduce the 520 movement activity and then make a decision to stay close to the food or escape. We noted that in 521 the case of the weaker storm, only a part of sea urchins left the food source. Remaining $S$. 522 intermedius individuals gathered into groups at the base of the feeders whereas M. nudus 523 specimens were on the surface of the feeders. However, unfortunately, we did not measure a 
524 velocity of water flow and, therefore, cannot correlate it with sea urchin movement activity.

525 Further studies are thus required to elucidate such a correlation.

526

\section{Sea urchin response to predation threat}

528 During this study, no successful starfish attacks on healthy sea urchins were observed for either 529 species, and only 3 cases of consuming of single ailing S. intermedius individuals by several

530

531

532

533

534

535

536

537

538

539

540

541

542

543

544

545

546

547

548

549

550

551

552

553 starfish specimens ( $P$. pectinifera and $L$. fusca) were recorded. Taking into account the laboratory experimental data that the starfish, L. anthosticta and P. pectinifera in particular, are predators of M. nudus (see for review Agatsuma, 2013b), we further analyzed the video records of 2017 captured by 6 video cameras in the course of another project. During 44 days, $132 \pm 46$ of M. nudus individuals were in the cameras' field of view and no cases of predator attacks were recorded (P.M. Zhadan pers. comm., 2018). Considering also that both sea urchin species showed only a weak response to sea stars even during direct contact, we can conclude that none of 6 starfish species observed on the feeders (P. pectinifera, L. fusca, A. amurensis, D. nipon, L. anthosticta and A. japonica) are specialized predators of S. intermedius and M. nudus. Most likely, starfish perform the function of scavengers.

The alarm response of $S$. intermedius to predation depended on the type of alarm signal and involved several phases. The sea urchins: (1) moved away from a source of threat (so called 'flight response'), (2) exhibited grouping behavior forming dense two-dimensional groups close to the food source, (3) left the food source, and (4) restored the initial spatial distribution on the food source. Phase 3 was most pronounced when the alarm signals were the attack of starfish on ailing specimens or simulated attack with crushed conspecifics: approximately $50 \mathrm{~h}$ after the beginning of starfish attack, there remained only $30-50 \%$ of sea urchins on the feeders. When the alarm signal was a simulated attack with crushed heterospecifics, phase 3 was much weakly pronounced or absent.

Sea urchins $M . n u d u s$ exhibited a fast (during $4 \mathrm{~h}$ ) escape (flight response) and prolonged (up to 19 days) avoidance of the source of attractive food near which the conspecifics were crushed. Such a long fear effect of the alarm signal associated with crushed conspecifics is probably due to the marking of the area with substances released by injured sea urchins. At the same time, $M$. nudus exhibited no responses to damaged heterospecifics. 
554

555

556

557

558

559

560

561

562

563

564

565

566

567

568

569

570

571

572

573

574

575

576

577

578

579

580

581

582

583

584

Escape of sea urchins from an alarm source is the most well-documented first phase of the alarm response of sea urchins (Snyder \& Snyder, 1970; Parker \& Shulman, 1986; Sheibling \& Hamm, 1991; Campbell et al., 2001; Hagen et al., 2002; Vadas \& Elner, 2003; Urriago et al., 2011; Wirtz \& Duarte, 2012). It has been shown that the alarm reaction in sea urchins started within a few minutes of exposure to waterborne chemosensory cues from some potential predators (fish, lobsters, crabs, sea stars, gastropods), as well as from crushed prey, conspecifics or heterospecifics. Generally, escape response was most pronounced in the experiments with damaged conspecifics.

To date, responses to chemosensory cues from damaged conspecifics have been demonstrated in several sea urchin species: Diadema antillarum (Kintzing \& Butler, 2014a; Snyder \& Snyder, 1970), S. droebachiensis (Hagen et al., 2002; Mann, 1982), Echinometra viridis and Lytechinus williamsi (Parker \& Shulman, 1986), Echinometra lucunter (Morishita \& Barreto, 2011; Parker \& Shulman, 1986), Echinus esculentus and Psammechinus miliaris (Campbell et al., 2001), Lytechinus variegatus and Tripneustes ventricosus (Vadas \& Elner, 2003), and Arbacia lixula and Sphaerechinus granularis (Wirtz \& Duarte, 2012). It should be noted, however, that Parker \& Shulman (1986) did not find an alarm reaction to extracts of conspecifics when analyzing sea urchin motion for $1 \mathrm{~min}$ in Eucidaris tribuloides, T. ventricosus and $L$. variegatus living in long, dense seagrass that provided protection from detection by predators, and D. antillarum occupying crevices.

In our studies, both $M$. nudus and S. intermedius exhibited a phased escape response to crushed conspecifics: (1) a sharp increase in locomotion speed just after presentation of an alarm signal lasting for $1-1.5 \mathrm{~h}$ and resulting in an increase of a distance from a threat source and grouping close to a food source (S. intermedius) or escape of approximately half of specimens (M. nudus), (2) deceleration lasting for approximately $1 \mathrm{~h}$ in $M$. nudus and $16 \mathrm{~h}$ in S. intermedius, and (3) the second increase in locomotion speed lasting for approximately $1.5 \mathrm{~h}$ and resulting in association dispersion and repopulation of feeders (S. intermedius) or escape of all remaining specimens (M. nudus). Previously, Vadas \& Elner (2003) found in the field experiments that two sympatric tropical sea urchin species, L. variegatus and T. ventricosus, demonstrated an initial burst of speed followed by a gradual deceleration up to relatively stable level in response to conspecific alarm cues. However, these movement reactions were much shorter and lasted only 2 min each. 
585

The most striking difference of these sea urchins in the escape responses to conspecific

586 alarm cues was that $M$. nudus exhibited fast and total escape whereas only a part of $S$.

587 intermedius individuals left a food source, and the remaining specimens formed associations on

588 the feeder and in close vicinity to it. Our results showed that grouping behavior is a common

589 phase of the alarm response in S. intermedius but not in M. nudus. As it was shown in laboratory 590 and field studies, a number of sea urchin species are capable of forming dense groups on a food 591 substrate (Bernstein et al., 1981, 1983; Garnick, 1978; Pearse, 2006; Vadas \& Elner, 2003).

592 Bernstein et al. $(1981,1983)$ found that the presence of predators (lobsters Homarus americanus 593 or crabs Cancer irroratus) in laboratory aquariums or in field cages triggered the formation of $S$. 594 droebachiensis aggregations that were larger than groups of feeding and non-feeding sea urchins 595 in the absence of predators. The researchers interpreted such aggregation behavior as a defense 596 mechanism of S. droebachiensis against predation. Vadas et al. (1986), however, did not find a 597 tendency to form aggregations in the same species in the presence of predators (decapods $H$. 598 americanus, C. irroratus and sea star Asterias vulgaris) and suggested that grouping of sea 599 urchins in tank corners or on tank walls/cage mesh may be an experimental artefact caused by 600 the accumulation of sea urchins near artificial obstacles that prevented them from escaping a 601 predator. This point of view was supported by other studies on interactions between sea urchins 602 S. droebachiensis and their predators in field and laboratory experiments (Harding \& Scheibling, 603 2015; Scheibling \& Hamm, 1991). In addition, Vadas \& Elner (2003), investigating the reactions 604 of sympatric sea urchins L. variegatus and T. ventricosus to simulated predator attacks in field 605 experiments, also found no formation of sea urchin groups in response to an alarm signal and 606 concluded that the flight response is the primary, and perhaps only defensive behavior employed 607 by these species. However, our results showed that two other sympatric sea urchin species $(M$. 608 nudus and S. intermedius) exhibit distinctly different behavioral response strategies to predation 609 risk: $M$. nudus employs fast escape and prolonged avoidance of dangerous area while $S$.

610 intermedius employs both grouping and escape behaviors.

611 The duration of the alarm response of $S$. intermedius (from the appearance of the alarm 612 signal to the return to feeding) was different under different conditions. It was the longest 613 (approximately $90 \mathrm{~h}$ ) after the attack of sea stars on ailing individuals. The eating of prey lasted 614 from 45 to $70 \mathrm{~h}$, and after that, from 20 to $45 \mathrm{~h}$ passed before sea urchins restored their original 615 arrangement on the feeder. Considering that semidiurnal tidal cycles and constant wave activity 
616 took place in the study areas, there is little reason to believe that a waterborne chemical cue from 617 the primary source (injured prey) could have persisted. The secondary source of the alarm signal 618 could be the products of predator metabolism (Scherer \& Smee, 2016). For example, black sea 619 urchin E. lucunter is able to distinguish sea stars feeding on conspecifics or closely related 620 species (Morishita \& Barreto, 2011). For predatory fish, it has been shown that substances that 621 cause the alarm response in the prey can remain active after passing through the digestive tract 622 (Manassa \& McCormick, 2012). In addition, it is likely that waterborne chemical cues from 623 predators and/or injured prey may be sorbed on the bottom sediments and gradually released, 624 thereby increasing the time of the alarm reaction in prey.

625 Based on the above data, it may be assumed that the duration of the alarm reaction of sea 626 urchins depends on two main factors: (1) the duration of the release of substances from predators 627 and/or injured prey to the environment, and (2) the time during which sea urchins can detect 628 these substances sorbed on the sediment. In addition, species-specific previous learning might 629 also be a factor determining different behavioral patterns in sea urchin species (Ferrari et al., 630 2010).

631 In our study, sea urchins M. nudus exhibited unique prolonged avoidance behavior in 632 response to crushed conspecifics, and this behavior has not been described before in sea urchins 633 and other echinoderms. The ability of M. nudus to avoid a site of predation for up to 19 days and 634 return to the food source only after a storm indicates that crushed M. nudus specimens released 635 some stable substances that marked the bottom for a long time and served as an alarm signal and 636 that the disruption and removal of the upper sediment layer during the storm probably 637 contributed to the removal of the alarm signal. The experiments with storm imitation support this 638 suggestion.

639

640 Possible mechanisms underlying the difference in sea urchin alarm responses

641 The mechanisms underlying different patterns of the alarm responses in cohabiting sea urchin 642 species are not yet understood. We believe that both the ability of $S$. intermedius to form 643 associations close to a food source and the ability of $M$. nudus to leave the area of predation risk 644 for a long period are useful evolutionary adaptations that enhance the likelihood of species 645 survival under permanent pressure from visual predators. 
We suggest that sea urchin $S$. intermedius uses camouflage to protect itself from visual

647 predators because a group of these sea urchins forms a grey spot of irregular shape decorated

648 with algae, which is more difficult to be identified from air or under water than a single object

649 with a regular round shape. Furthermore, a solitary sea urchin is easier to be captured by a diving

650 predator. At the same time, such camouflage cannot be effective for sea urchin $M$. nudus because

651 its black color is in high contrast to the color of the bottom, whereas leaving the area occupied by

652 a predator increases the chances of $M$. nudus survival.

653 It is well known that in temperate waters, the most active consumers of sea urchins that

654 are able to control their abundance are the sea otter Enhydra lutris (Duggins, 1980; Estes \&

655 Duggins, 1995; Watson \& Estes, 2011) and a number of bird species, mainly gulls (Guillemette

656 et al., 1992; Himmelman \& Steele, 1971; Hori \& Noda, 2007; Merkel et al., 2007; Wootton,

657 1995). Wootton (1995) compared the densities of sea urchin Strongylocentrotus purpuratus in

658 several places in a lower intertidal zone both exposed to bird predators (glaucous-winged gulls

659 Larus glaucescens, American black oyster catchers Haematopus bachmani and northwestern

660 crows Corvus caurinus) and protected from birds by cages and showed that sea urchin

661 abundance was 59\% lower after 1 year and 45\% lower after 2 years in the presence of bird

662 predators compared to the absence of bird predators. For S. intermedius, the most abundant avian

663 predators are carrion crow Corvus corone and a few gull species that are able to consume a large

664 number of sea urchins, more than 4,000 specimens per 1 ha (Hori \& Noda, 2007).

665 Data on the geographical distributions of S. intermedius and M. nudus (Agatsuma, 2013a,

666 2013b; Bazhin, 1998; Kafanov \& Pavlyuchkov, 2001) and the sea otter (Kenyon, 1969) give

667 evidence that the ranges of these species may have partially overlapped in the past, but at

668 present, the overlapping of this predator-prey habitat seems more likely for temperate-boreal

669 species, S. intermedius, which inhabits the Asian Pacific coastal waters from the Kamchatka

670 Peninsula southward to the Korean Peninsula and from the Russian coast eastward to the

671 Japanese Islands. The sea urchin M. nudus is a subtropical species, and coastal waters of the Sea

672 of Japan near Russia (Primorye Region) and Japan (northern Hokkaido) represent the northern

673 part of its range, whereas for the sea otter, the northern Hokkaido represented the southern

674 boundary of its range in the northwestern Pacific until the 18th century, before fur hunting began

675 (Wilson et al., 1991). 
Sea otters and predatory birds prefer sea urchins of medium and large size, i.e., adult

677 specimens contributing to population reproduction (Estes \& Duggins, 1995; Guillemette et al.,

678 1992; Himmelman \& Steele, 1971; Hori \& Noda, 2007). The defensive behaviors of sea urchins

679 S. intermedius and M. nudus could have formed mainly under the pressure of these predators.

680 Due to natural selection, the individuals that could avoid predation attacks survived, and useful

681 genetic traits have been passed from generation to generation in the form of different defensive

682 behaviors.

683

684 CONCLUSION

685 Our results show that cohabiting sea urchin species, S. intermedius and M. nudus, which were 686 monitored in their natural environment under conditions of food abundance display both similar 687 and different behavioral responses to hydrodynamics and predation threat. The most interesting 688 findings are the following: (1) under calm weather, S. intermedius but not $M$. nudus tended to 689 group on the food substrate; movement patterns of both sea urchins were similar but M. nudus 690 exhibited the higher locomotion speed and distance travelled; (2) both sea urchins responded to 691 increased wave activity by a sharp decrease in the movement activity up to almost complete stop 692 and then made a decision to stay close to the food or escape; (3) several sea star species failed to 693 predate on healthy sea urchins of both species, and only a few starfish attacks on ailing $S$.

694 intermedius specimens were successful; (4) the alarm response of $S$. intermedius depended on the 695 type of alarm signal (consumption of ailing conspecifics by starfish or simulated attack) and 696 included the formation of dense groups close to the food source; (5) the alarm response of $S$. 697 intermedius lasted approximately $90 \mathrm{~h}$ and $20 \mathrm{~h}$ for starfish attacks on ailing conspecifics and for 698 simulated attacks (crushed conspecifics or heterospecifics), respectively; (6) M. nudus responded 699 to crushed conspecifics only and exhibited no grouping behavior but displayed fast escape 700 (during $4 \mathrm{~h}$ ) and prolonged (up to 19 days) avoidance of the food source; (7) both sea urchins 701 exhibited a phased escape response to crushed conspecifics consisting of a sharp increase in 702 locomotion speed just after presentation of the alarm signal followed by deceleration, and the 703 second increase in locomotion speed associated with repopulation of feeders (S. intermedius) or 704 complete escape (M. nudus); (8) damaged specimens of $M$. nudus released some stable alarm 705 substances. Furthermore, our results show the benefits of using continuous time-lapse video 706 recording to study the long-term behavioral responses of sea urchins to different disturbing 
707 factors such as high hydrodynamic activity and predation threat. Considering the important

708 ecological role of sea urchins as grazers of marine plants, data on the duration of the fear

709 response in sea urchin species, i.e., the periods when their foraging activity is inhibited, may be

710 of greatest use in mathematical modelling of the marine ecosystem.

711

712 ACKNOWLEDGEMENTS

713 We thank M.Yu. Cheranev for the help in making the underwater installation for video recording

714 and L.Yu. Pavin for assistance in the field. We also wish to express our gratitude to the

715 anonymous reviewer for the valuable comments and pertinent suggestions that led to

716 improvement in the presentation of our results.

717

718 REFERENCES

719 Abrams PA. 1995. Implications of dynamically variable traits for identifying, classifying, and

720 measuring direct and indirect effects in ecological communities. American Naturalist

721 146(1): 112-134 DOI 10.1086/285789.

722

Agatsuma Y. 2013a. Strongylocentrotus intermedius. In: Lawrence JM, ed. Sea Urchins:

723 Biology and Ecology. Elsevier B.V., 438-447 DOI 10.1016/B978-0-12-396491-5.00028-

724 9.

725

Agatsuma Y. 2013b. Strongylocentrotus nudus. In: Lawrence JM, ed. Sea Urchins: Biology and 726 Ecology. Elsevier B.V., 449-460 DOI 10.1016/B978-0-12-396491-5.00029-0.

727

728

729

730

731

732

Bazhin AG. 1998. The sea urchin genus Strongylocentrotus in the seas of Russia: taxonomy and ranges. In: Mooi R, Telford M, eds. Echinoderms: Proceedings of the 9th International Echinoderm Conference, San Francisco, August 1996. Rotterdam: Balkema, 563-566.

Bernstein BB, Schroeter SC, Mann KH. 1983. Sea urchin (Strongylocentrotus droebachiensis) aggregating behavior investigated by a subtidal multifactorial experiment. Canadian Journal of Fisheries and Aquatic Sciences 40:1975-1986 DOI 10.1139/f83-227. 
733 Bernstein BB, Williams BE, Mann KH. 1981. The role of behavioral responses to predators in

734

735

736

737

738

739

740

741

742

743

744

745

746

747

748

749

750

751

752

753

754 modifying urchins' (Strongylocentrotus droebachiensis) destructive grazing and seasonal foraging patterns. Marine Biology 63:39-49 DOI 10.1007/BF00394661.

Campbell AC, Coppard S, Abreo CD, Tudor-Thomas R. 2001. Escape and aggregation responses of three echinoderms to conspecific stimuli. Biological Bulletin 201:175-185 DOI https://www.journals.uchicago.edu/doi/abs/10.2307/1543332?journalCode=bbl.

Cannone AJ. 1970. The anatomy and venom-emitting mechanism of the globiferous pedicellariae of the urchin Parechinus angulosis (Leske) with notes on their behaviour. Zoologica Africana 5:179-190 DOI https://www.ajol.info/index.php/az/article/view/152472/142062

Chivers DP, Smith JF. 1998. Chemical alarm signalling in aquatic predator-prey systems: a review and prospectus. Ecoscience 5:338-352 DOI 10.1080/11956860.1998.11682471.

Clemente S, Hernandez JC, Montano-Moctezuma G, Russell M, Ebert TA. 2013. Predators of juvenile sea urchins and the effect of habitat refuges. Marine Biology 160(3):579-590 DOI 10.1007/s00227-012-2114-3.

Crook AC, Long M, Barnes DKA. 2000. Quantifying daily migration in the sea urchin Paracentrotus lividus. Journal of the Marine Biological Association of the UK 80(1):177-178 DOI10.1017/S0025315499001721.

\section{Cohen-Rengifo M, Agüera A, Detrain C, Bouma TJ, Dubois P, Flammang P. 2018.} Biomechanics and behaviour in the sea urchin Paracentrotus lividus (Lamarck, 1816) when facing gradually increasing water flows. Journal of Experimental Marine Biology and Ecology 506:61-71 DOI10.1016/j.jembe.2018.05.010. 
755 Dance C. 1987. Patterns of activity of the sea urchin Paracentrotus lividus in the Bay of Port-

756

757

758

759

760

761

762

763

764

765

766

767

768

769

770

771

772

773

774

775

776

777 Cros (Var, France, Mediterranean). Marine Ecology 8:131-142 DOI 10.1111/j.14390485.1987.tb00179.x.

Dill LM, Heithaus MR, Walters CJ. 2003. Behaviorally mediated indirect interactions in marine communities and their conservation implications. Ecology 84(5):1151-1157 DOI 10.1890/0012-9658(2003)084[1151:BMIIIM]2.0.CO;2.

Duggins DO. 1980. Kelp beds and sea otters: an experimental approach. Ecology 61: 447-453 DOI $10.2307 / 1937405$.

Dumont CP, Himmelman JH, Russell MP. 2006. Daily movement of the sea urchin Strongylocentrotus droebachiensis in different subtidal habitats in eastern Canada. Marine Ecology Progress Series 317:87-99 DOI 0.3354/meps317087.

Dumont CP, Himmelman JH, Robinson SMC. 2007. Random movement pattern of the sea urchin Strongylocentrotus droebachiensis. Journal of Experimental Marine Biology and Ecology 340:80-89 DOI 10.1016/j.jembe.2006.08.013.

Estes JA, Duggins DO. 1995. Sea otters and kelp forests in Alaska: generality and variation in a community ecological paradigm. Ecological Monographs 65:75-100 DOI $10.2307 / 2937159$.

Ferrari MCO, Wisenden BD, Chivers DP. 2010. Chemical ecology of predator-prey interactions in aquatic ecosystems: a review and prospectus. Canadian Journal of Zoology 88:698-724 DOI 10.1139/Z10-029.

Frey DL, Gagnon P. 2016. Spatial dynamics of the green sea urchin Strongylocentrotus droebachiensis in food-depleted habitats. Marine Ecology Progress Series 552:223-240 DOI https://doi.org/10.3354/meps11787. 
778 Freeman A. 2006. Size-dependent trait-mediated indirect interactions among sea urchin 779 herbivores. Behavioral Ecology 17:182-187 DOIhttps://doi.org/10.1093/beheco/arj014.

780 Fricke HW. 1973. Behaviour as part of ecological adaptation. In situ studies in the coral reef. 781 Helgoländer Wissenschaftliche Meeresuntersuchungen 24:120-144

782 DOIhttps://link.springer.com/article/10.1007/BF01609505.

783

784

785

786

787

788

789

790

791

792

793

794

795

796

797

798

799

Garnick E. 1978. Behavioral ecology of Strongylocentrotus droebachiensis (Muller) (Echinodermata: Echinoidea). Aggregating behavior and chemotaxis. Oecologia (Berl.) 37:77-84 DOI10.1007/BF00349993.

Guillemette M, Ydenberg RC, Himmelman JH. 1992. The role of energy intake rate in prey and habitat selection of common eiders Somateria mollissima in winter: a risk-sensitive interpretation. Journal of Animal Ecology 61:599-610 DOI10.2307/5615.

Hagen NT, Andersen A, Stabell OB. 2002. Alarm responses of the green sea urchin, Strongylocentrotus droebachiensis, induced by chemically labeled durophagus predators and simulated acts of predation. Marine Biology 140:365-374 DOI10.1007/s002270100694.

Hagen NT, Mann KH. 1994. Experimental analysis of factors influencing the aggregating behavior of the green sea urchin Strongylocentrotus droebachiensis (Müller). Journal of Experimental Marine Biology and Ecology 176:107-126 DOI10.1016/00220981(94)90200-3.

Harding APC, Scheibling RE. 2015. Feed or flee: effect of a predation-risk cue on sea urchin foraging activity. Journal of Experimental Marine Biology and Ecology 466:59-69 DOIhttps://doi.org/10.1016/j.jembe.2015.02.005. 
800 Hasegawa K. 2014. Analysis of circadian rhythm in Strongylocentrotus nudus using a

801

802

803

804

805

806

807

808

809

810

811

812

813

814

815

816

817

818

819

820

821

commercial digital camera with an interval function. Reports of Marine Ecology

Research Institute (MERI, Tokyo) 18:63-65 (in Japanese).

http://www.kaiseiken.or.jp/english/meri_report2017.pdf.

Hereu B, Zabala M, Linares C, Sala E. 2005. The effects of predator abundance and habitat structural complexity on survival of juvenile sea urchins. Marine Biology 146:293-299 DOI https://link.springer.com/article/10.1007/s00227-004-1439-y.

Himmelman JH, Steele DH. 1971. Foods and predators of the green sea urchin Strongylocentrotus droebachiensis in Newfoundland waters. Marine Biology 9:315-322 DOI10.1007/BF00372825.

Hori M, Noda T. 2007. Avian predation on wild and cultured sea urchin Strongylocentrotus intermedius in a rocky shore habitat. Fisheries Science 73(2):303-313 DOI0.1111/j.1444-2906.2007.01336.x.

James DW. 2000. Diet, movement, and covering behavior of the sea urchin Toxopneustes roseus in rhodolith beds in the Gulf of California, México. Marine Biology 137:913-923 DOI $10.1007 / \mathrm{s} 002270000423$.

Jensen M. 1966. The response of two sea-urchins to the sea-star Marthasterias glacialis (L.) and other stimuli. Ophelia 3:209-219 DOI https://doi.org/10.1080/00785326.1966.10409643.

Kafanov AI, Pavlyuchkov VA. 2001. Ecology of the commercial sea urchins (genus Strongylocentrotus) of continental Japan Sea. Proceedings of the Pacific Research Institute of Fisheries and Oceanography (TINRO-Center) 128(2):349-373 (in Russian with English summary). 
822 Kawamata S. 1998. Effect of wave-induced oscillatory flow on grazing by a subtidal sea urchin

823

824

825

826

827

828

829

830

831

832

833

834

835

836

837

838

839

840

841

842

Strongylocentrotus nudus (A. Agassiz). Journal of Experimental Marine Biology and Ecology 224:31-48 DOIhttps://doi.org/10.1016/S0022-0981(97)00165-2.

Kenyon KW. 1969. The sea otter in the eastern Pacific Ocean. North American Fauna 68:1-352 DOI10.3996/nafa.68.0001.

Kintzing MD, Butler MJ. 2014a. The influence of shelter, conspecifics, and threat of predation on the behavior of the long-spined sea urchin (Diadema antillarum). Journal of Shellfish Research 33:3781-3785 DOI10.2983/035.033.0312.

Kintzing MD, Butler MJ. 2014b. Effects of predation upon the long-spined sea urchin Diadema antillarum by the spotted spiny lobster Panulirus guttatus. Marine Ecology Progress Series 495:185-191 DOI10.3354/meps10568.

Lauzon-Guay J-S, Scheibling RE, Barbeau MA. 2006. Movement patterns in the green sea urchin, Strongylocentrotus droebachiensis. Journal of the Marine Biological Association of the UK 86:167-174 DOIhttps://doi.org/10.1017/S0025315406012999.

Lauzon-Guay J-S, Scheibling RE. 2007. Behaviour of sea urchin Strongylocentrotus droebachiensis grazing fronts: food-mediated aggregation and density-dependent facilitation. Marine Ecology Progress Series 329:191-204 DOIhttp://dx.doi.org/10.3354/meps329191.

Lima SL. 1998. Non lethal effects in the ecology of predator-prey interactions. What are the ecological effects of anti-predator decision-making? BioScience 48(1):25-34 DOIhttps://doi.org/10.2307/1313225. 
843 Lima SL, Dill LM. 1990. Behavioral decisions made under the risk of predation: a review and

844

845

846

847

848

849

850

851

852

853

854

855

856

857

858

859

860

861

862

863

864 prospectus. Canadian Journal of Zoology 68:619-640 DOIhttps://doi.org/10.1139/z90092.

Lissner AL. 1980. Some effects of turbulence on the activity of the sea urchin Centrostephanus coronatus Verrill. Journal of Experimental Marine Biology and Ecology 48:185-193 DOI https://doi.org/10.1016/0022-0981(80)90016-7.

Machiguchi Y. 1987. Feeding behavior of sea urchin Strongylocentrotus intermedius (A. Agassiz) observed in Y-shaped chamber. Bulletin of the Hokkaido Regional Fisheries Research Institute 51:33-37 (in Japanese with English abstract).

Machiguchi Y, Mizutori S, Sanbonsuga Y. 1994. Food preference of sea urchin Strongylocentrotus nudus in laboratory. Bulletin of the Hokkaido National Fisheries Research Institute 58:35-43 (in Japanese with English abstract).

Manassa RP, McCormick MI. 2012. Risk assessment via predator diet cues in a coral reef goby. Journal of Experimental Marine Biology and Ecology 426-427:48-52 DOIhttps://doi.org/10.1016/j.jembe.2012.05.023.

Mann KH. 1982. Kelp, sea urchins and predators: a review of strong interactions in rocky subtidal systems of eastern Canada, 1970-1980. Netherlands Journal of Sea Research 16:414-423 DOIhttps://doi.org/10.1016/0077-7579(82)90047-3.

Manzur T, Navarrete SA. 2011. Scales of detection and escape of the sea urchin Tetrapygus niger in interactions with the predatory sun star Heliaster helianthus. Journal of Experimental Marine Biology and Ecology 407:302-308 DOIhttps://doi.org/10.1016/j.jembe.2011.06.025. 
865 Matassa CM. 2010. Purple sea urchins Strongylocentrotus purpuratus reduce grazing rates in

866

867

868

869

870

871

872

873

874

875

876

877

878

879

880

881

882

883

884

885

response to risk cues from the spiny lobster Panulirus interruptus. Marine Ecology

Progress Series 400:283-288 DOI https://doi.org/10.3354/meps08425.

Merkel FR, Mosbech A, Jamieson SE, Falk K. 2007. The diet of king eiders wintering in Nuuk, Southwestern Greenland, with reference to sympatric wintering common eiders. Polar Biology 30:1593-1597 DOI https://doi.org/10.1007/s00300-007-0321-z.

Morishita VR, Barreto RE. 2011. Black sea urchins evaluate predation risk using chemical signals from a predator and injured con- and heterospecific prey. Marine Ecology Progress Series 435:173-181 DOIhttp://dx.doi.org/10.3354/meps09253.

Morse B, Hunt H. 2013. Effect of unidirectional water currents on displacement behaviour of the green sea urchin Strongylocentrous droebachiensis. Journal of the Marine Biological Association of the UK 93(7):1923-1928 DOIhttps://doi.org/10.1017/S002531541300060X.

Parker DA, Shulman MJ. 1986. Avoiding predation: alarm responses of Caribbean sea urchins to simulated predation on conspecific and heterospecific sea urchins. Marine Biology 93:201-208 DOI https://doi.org/10.1007/BF00508257.

Pearse JS. 2006. Ecological role of purple sea urchins. Science 314:940-941 DOI 10.1126/science. 1131888 .

Pearson DE. 2010. Trait- and density-mediated indirect interactions initiated by an exotic invasive plant autogenic ecosystem engineer. American Naturalist 176(4):394-403 DOI https://doi.org/10.1086/656274.

PeerJ reviewing PDF | (2019:05:38071:2:0:NEW 17 Oct 2019) 
886 Scheibling RE, Hamm J. 1991. Interactions between sea urchins (Strongylocentrotus

887

888

889

890

891

892

893

894

895

896

897

898

899

900

901

902

903

904

905

906

907

droebachiensis) and their predators in field and laboratory experiments. Marine Biology

110:105-116 DOI https://doi.org/10.1007/BF01313097.

Scherer AE, Smee DL. 2016. A review of predator diet effects on prey defensive responses. Chemoecology 26(3):83-100 DOI 10.1007/s00049-016-0208-y.

Schmitz OJ, Krivan V, Ovadia O. 2004. Trophic cascades: the primacy of trait-mediated indirect interactions. Ecology Letters 7:153-163 DOIhttps://doi.org/10.1111/j.14610248.2003.00560.x.

Siddon CE, Witman JD. 2003. Influence of chronic, low-level hydrodynamic forces on subtidal community structure. Marine Ecology Progress Series 261:99-110 DOI10.3354/meps261099.

Snyder N, Snyder H. 1970. Alarm response of Diadema antillarum. Science 168:276-278 DOI10.1126/science.168.3928.276.

Spyksma AJP, Taylor RB, Shears NT. 2017. Predation cues rather than resource availability promote cryptic behaviour in a habitat-forming sea urchin. Oecologia 183(3):821-829 DOI10.1007/s00442-017-3809-4.

Steneck RS. 2013. Sea urchins as drivers of shallow benthic marine community structure. In: Lawrence JM, ed. Sea Urchins: Biology and Ecology. Elsevier B.V., 195-212 DOIhttps://doi.org/10.1016/B978-0-12-396491-5.00014-9.

Tamaki H, Muraoka D, Inoue T. 2018. Effect of water flow on grazing by the sea urchin (Strongylocentrotus nudus) in the presence of refuge habitat. Journal of Water and Environment Technology 16(1):30-39 DOI 0.2965/jwet.17-010. 
908 Tertschnig WP. 1989. Diel activity patterns and foraging dynamics of the sea urchin

909 Tripneustes ventricosus in a tropical seagrass community and a reef environment (Virgin

910 Islands). Marine Ecology 10(1):3-21 DOIhttps://doi.org/10.1111/j.1439-

$911 \quad$ 0485.1989.tb00063.x.

912 Trussell GC, Ewanchuk PJ, Matassa CM. 2006. Habitat effects on the relative importance of 913 trait and density-mediated indirect interactions. Ecology Letters 9:1245-1252.

914 DOI10.1111/j.1461-0248.2006.00981.x.

915 Tuya F, Martin JA, Luque A. 2004. Patterns of nocturnal movement of the long-spined sea 916 urchin Diadema antillarum (Philippi) in Gran Canaria (the Canary Islands, central East

917 Atlantic Ocean). Helgoland Marine Research 58:26-31 DOI

918 https://doi.org/10.1007/s10152-003-0164-0.

Ullrich-Lüter EM, Dupon TS, Arboleda E, Hausen H, Arnone MI. 2011. Unique system of

923

924

925

926

927

928

929 photoreceptors in sea urchin tube feet. Proceedings of the National Academy of Sciences of the United States of America 108(20):8367-8372 DOIhttps://doi.org/10.1073/pnas.1018495108.

Urriago JD, Himmelman JH, Gaymer CF. 2011. Responses of the black sea urchin Tetrapygus niger to its sea-star predators Heliaster helianthus and Meyenaster gelatinosus under field conditions. Journal of Experimental Marine Biology and Ecology 399:17-24 DOIhttps://doi.org/10.1016/j.jembe.2011.01.004.

Vadas RL, Elner RW, Garwood PE, Babb IG. 1986. Experimental evaluation of aggregation behavior in the sea urchin Strongylocentrotus droebachiensis. A reinterpretation. Marine Biology 90:433-448 DOI https://doi.org/10.1007/BF00428567. 
930 Vadas RL, Elner RW. 2003. Responses to predation cues and food in two species of sympatric,

931

932

933

934

935

936

937

938

939

940

941

942

943

944

945

946

947

948

949

950 tropical sea urchins. Marine Ecology 24(2):101-121 DOI https://doi.org/10.1046/j.14390485.2003.03817.x.

Watson JC, Estes JA. 2011. Stability, resilience and phase shifts in rocky subtidal communities along the west coast of Vancouver Island. Ecological Monographs 81(2):215-239 DOIhttps://doi.org/10.1890/10-0262.1.

Werner EE, Peacor SD. 2003. A review of trait-mediated indirect interactions in ecological communities. Ecology 84(5):1083-1100 DOIhttps://doi.org/10.1890/00129658(2003)084[1083:AROTII]2.0.CO;2.

Wilson DE, Bogan MA, Brownell RLJ, Burdin AM, Maminov MK. 1991. Geographic variation in sea otters, Enhydra lutris. Journal of Mammalogy 72(1):22-36 DOIhttps://doi.org/10.2307/1381977.

Wirtz P, Duarte J. 2012. Alarm reaction and absence of alarm reaction to simulated predation on conspecifics in two temperate sea urchin species. Arquipelago - Life and Marine Sciences 29:59-62 URI http://hdl.handle.net/10400.3/1440.

Wootton J. 1995. Effects of birds on sea urchin and algae: a lower-intertidal trophic cascade. Ecoscience 2(4):321-328.

Zhadan PM, Vaschenko MA, Ryazanov SD. 2018. Assessing the effect of environmental factors on the spawning activity of the sea urchin Strongylocentrotus intermedius through video recording observations. Marine Ecology Progress Series 588:101-119 DOIhttps://doi.org/10.3354/meps12436. 


\section{Figure 1}

Temporal dynamics of the numbers of sea urchins Mesocentrotus nudus and Strongylocentrotus intermedius in long-term experiments.

The experiments were conducted in: (A) Kievka Bay, 2014; (B) Kievka Bay, 2015; (C) Alekseev Bay, 2016. Blue and red circles connected by lines denote the numbers of $M$. nudus and $S$. intermedius, respectively, presented as the sum of all sea urchins of the given species on 4 feeders per each $6 \mathrm{~h}$ of observations (see Table S1 for original data). Triangles indicate the time points when sea urchins M. nudus were removed from the feeders. Upside down triangles denote the time points when sea urchins $M$. nudus were crushed near the feeders. Green squares denote the time points when the feeders were changed. Green rhombuses indicate the time points when the feeders were changed after the mimicking of stormy weather conditions. Shaded areas denote storm periods. Solid violet horizontal lines indicate periods of poor visibility because of high water turbidity. X-axis: month and date. 

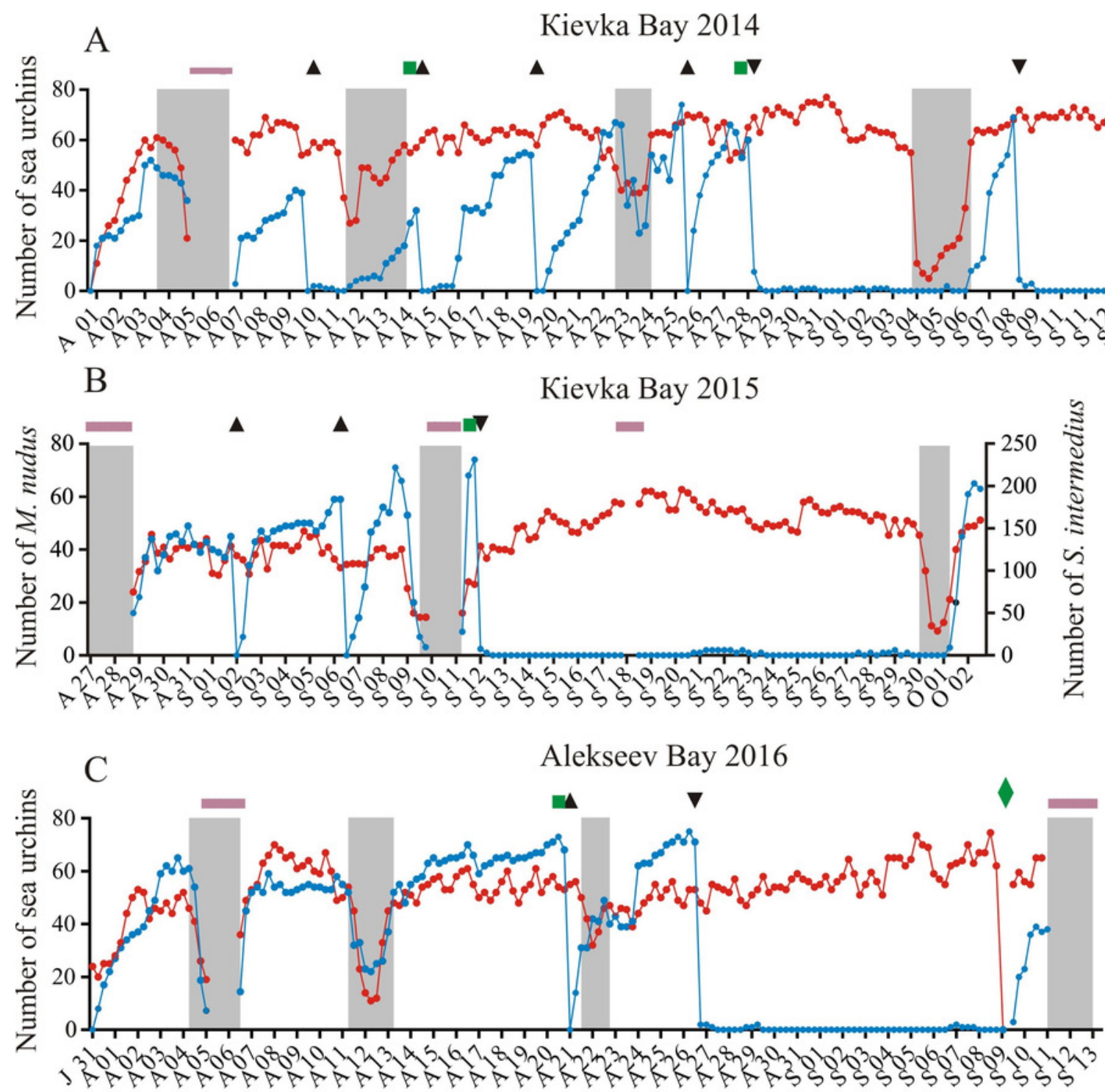


\section{Figure 2}

Changes in the numbers of sea urchins Mesocentrotus nudus (A) and Strongylocentrotus intermedius (B) in response to the stormy weather.

Range (whiskers), upper and lower quartile (box), mean (+), and median (solid line) of the numbers of sea urchins before, during and after the storm periods are presented. Different lowercase letters above the boxes indicate significant differences in sea urchin numbers: (A) the differences between 'before the storm' and 'during the storm' numbers are significant at $P<0.0001$, the differences between 'during the storm' and 'after the storm' numbers are significant at $P<0.001$ (1-way ANOVA followed by Tukey's multiple comparisons test), (B) the differences between 'before the storm' and 'during the storm' numbers, 'during the storm' and 'after the storm' numbers are significant at $P<0.0001$ (Kruskal-Wallis test followed by Dunn's multiple comparisons test). See Table S5 and Table S6 for raw data and statistics. 

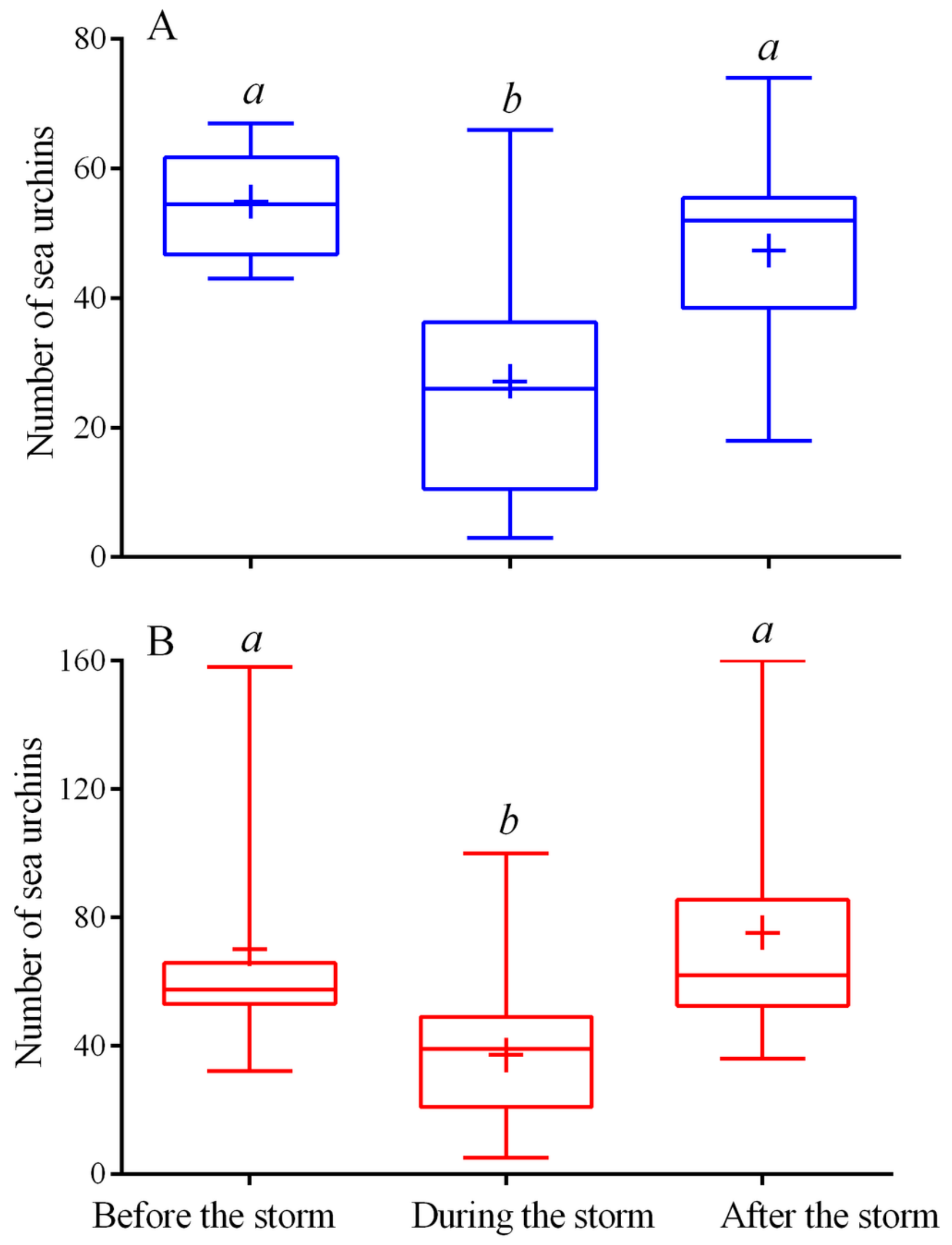


\section{Figure 3}

Movement activity of the sea urchins Strongylocentrotus intermedius in response to starfish attacks.

(A) Starfish attack on September 5, 2015. (B) Starfish attack on September 21, 2015. Red rhombuses denote sea urchin distances from the site of the attack, mean $\pm S D(n=13)$. Black squares connected by dashed line denote the sum number of 2 species of sea stars (Patiria pectinifera and Lethasterias fusca) at the site of the attack. Red circles connected by solid line denote the number of sea urchins in the cameras' field of view. Time of the beginning of the attack is indicated by black asterisk. 

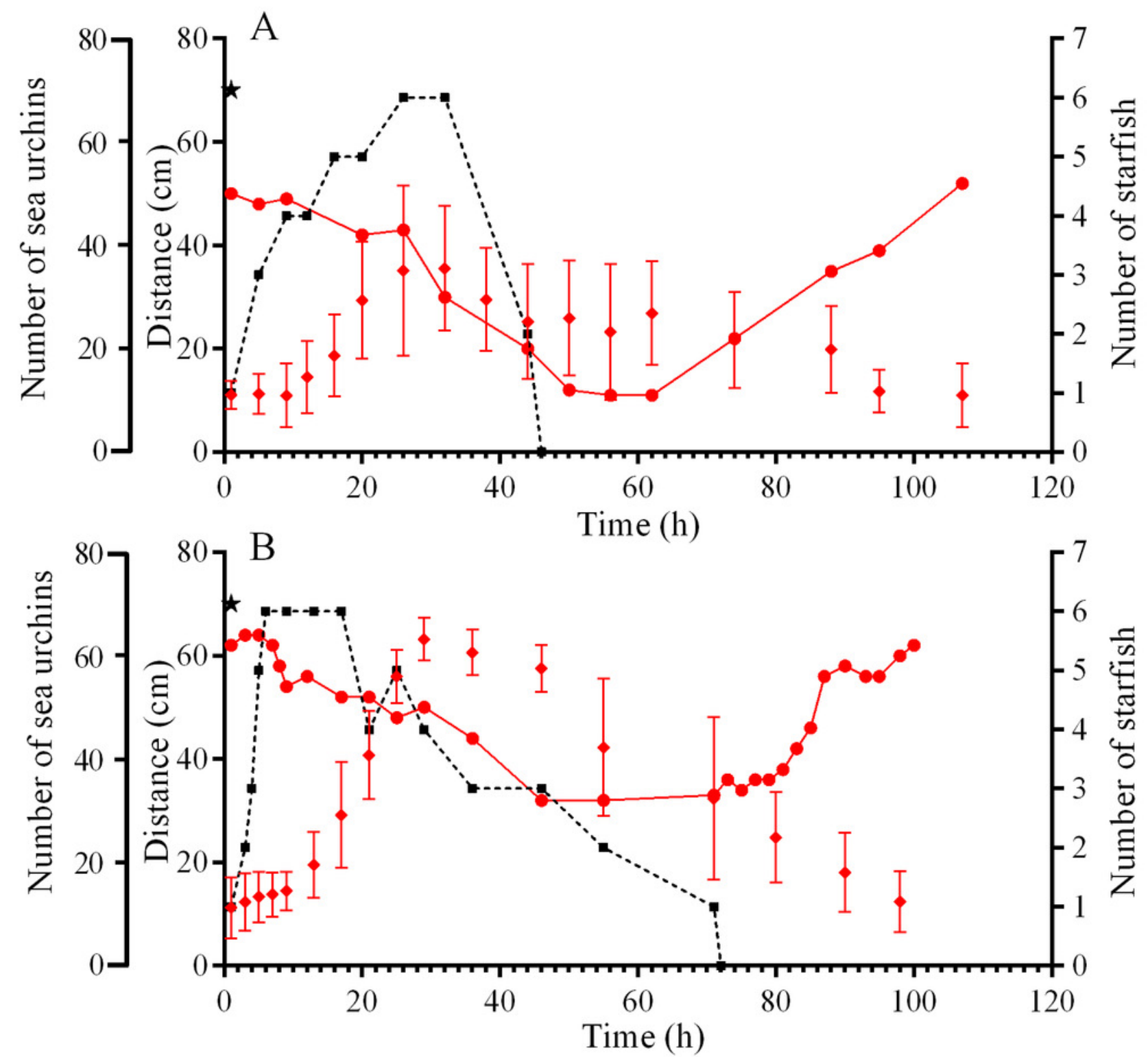
Figure 4

Changes in the numbers of sea urchins Mesocentrotus nudus during escape in response to crushed conspecifics in long-term experiments of 2014-2016.

The data of 4 experiments conducted during long-term recordings of 2014-2016 (see Fig. $1 \mathrm{~A}-\mathrm{C}$, Tables S1, S8) are presented as median and range of the number of $M$. nudus per $1 \mathrm{~h}$ after crushing of conspecifics. Nonlinear regression is significant $\left(R^{2}=0.9454\right.$, see Table S8 for raw data and statistics).

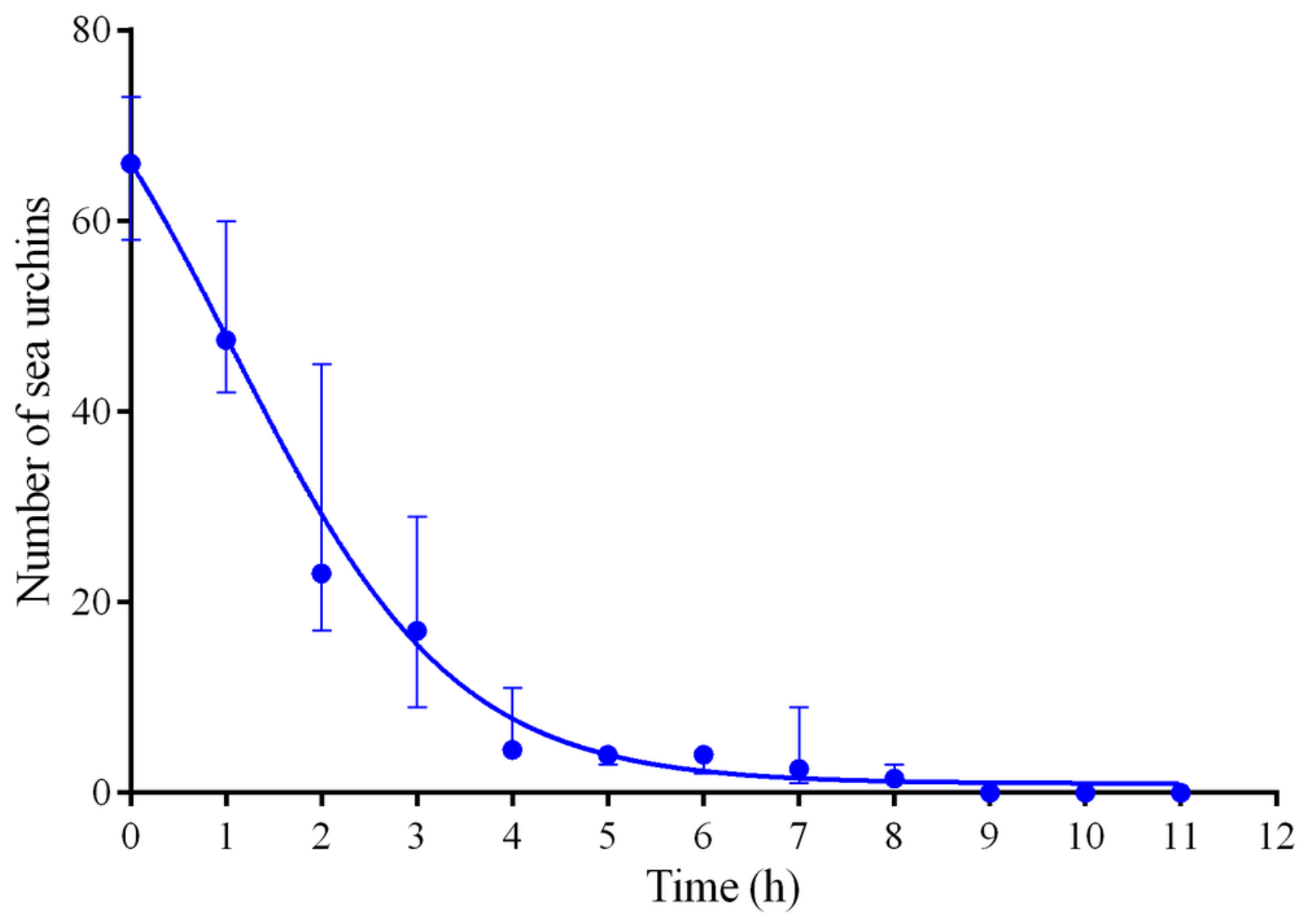


Figure 5

Movement activity of the sea urchins Mesocentrotus nudus in response to crushed conspecifics.

Blue solid line denotes the average step length of sea urchins $(n=10)$. Blue circles connected by dashed line denote the number of sea urchins in the cameras' field of view. Time point of treatment is denoted by upside down triangle.

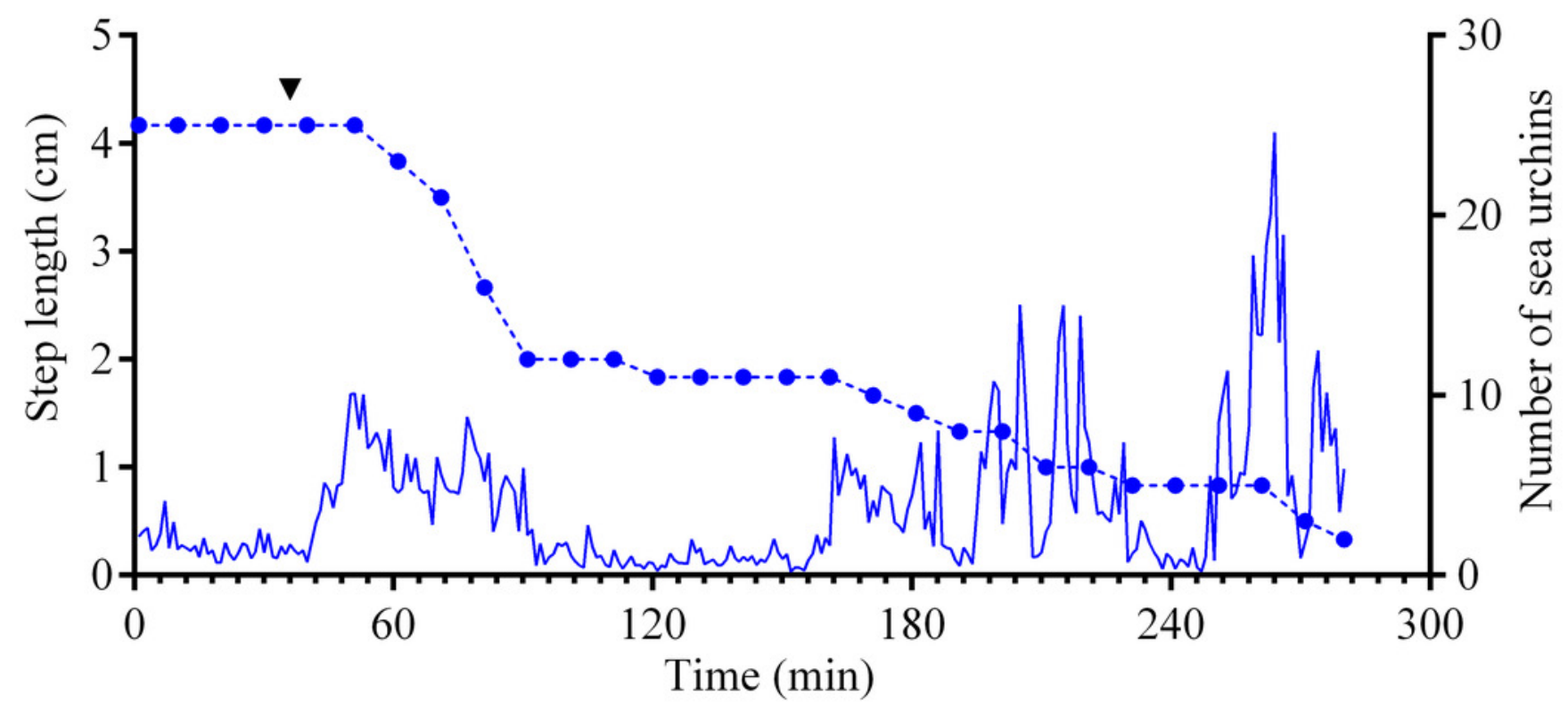


Figure 6

Temporal dynamics of repopulation of the feeders by sea urchins Mesocentrotus nudus after their removal in long-term experiments of 2014-2016.

The data of 4 experiments conducted during long-term recordings of 2014-2016 (Fig. 1A-C, Tables S1, S9) are presented as median and range of the number of $M$. nudus per $6 \mathrm{~h}$.

Nonlinear regression is significant $\left(R^{2}=0.731\right.$, see Table S9 for statistics).

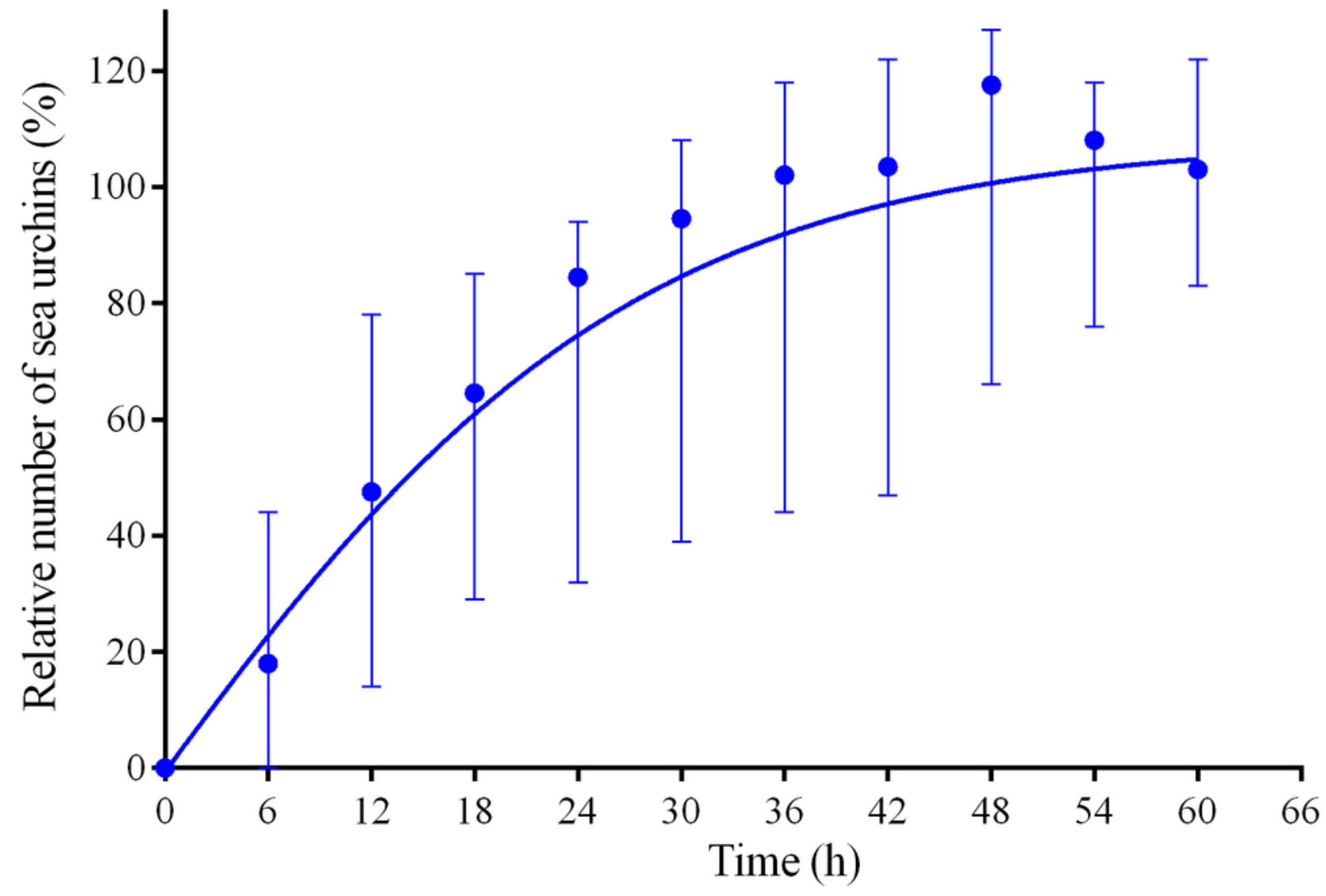


Figure 7

Movement activity of the sea urchins Mesocentrotus nudus (blue lines) and Strongylocentrotus intermedius (red lines) in response to crushed heterospecifics.

(A) The changes in the average step length of sea urchins $(n=10)$. (B) The changes in sea urchin distances from the site of simulated attack, mean \pm SD $(n=10)$. SD is shown for every sixth measurement. Time of the treatment is denoted by upside down triangle.
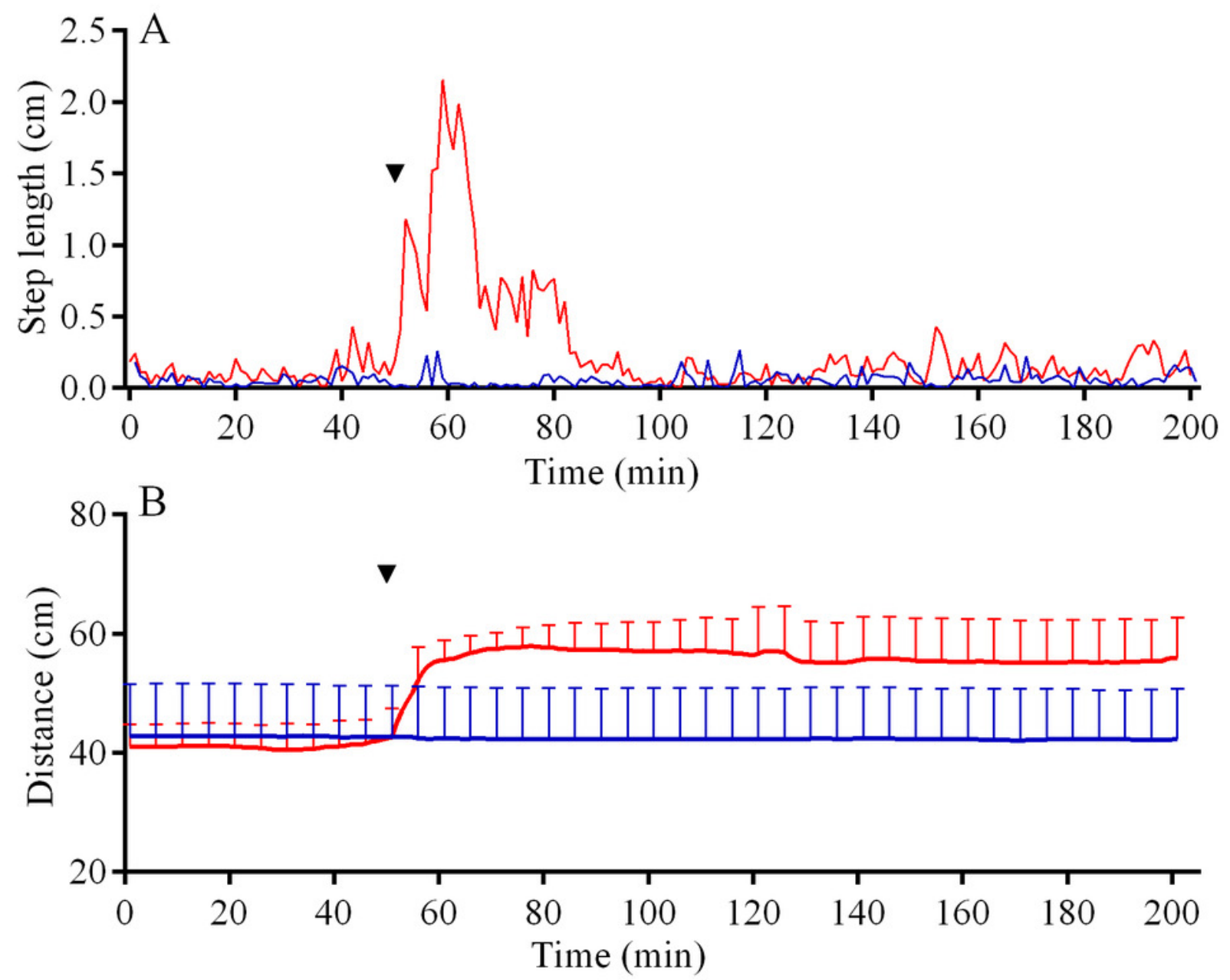


\section{Figure 8}

Temporal dynamics of the mean group size of sea urchins Strongylocentrotus intermedius in response to simulated predator attack.

(A) Response of S. intermedius to crushed conspecifics. (B) Response of S. intermedius to crushed specimens of the sea urchin Mesocentrotus nudus. The mean group size is presented as box-whisker plot showing the median (solid line), range (whiskers) and upper and lower quartiles (box). Upside down triangles denote the time points when sea urchins were crushed near the feeders. See Table S14 and Table S17 for raw data and statistics.
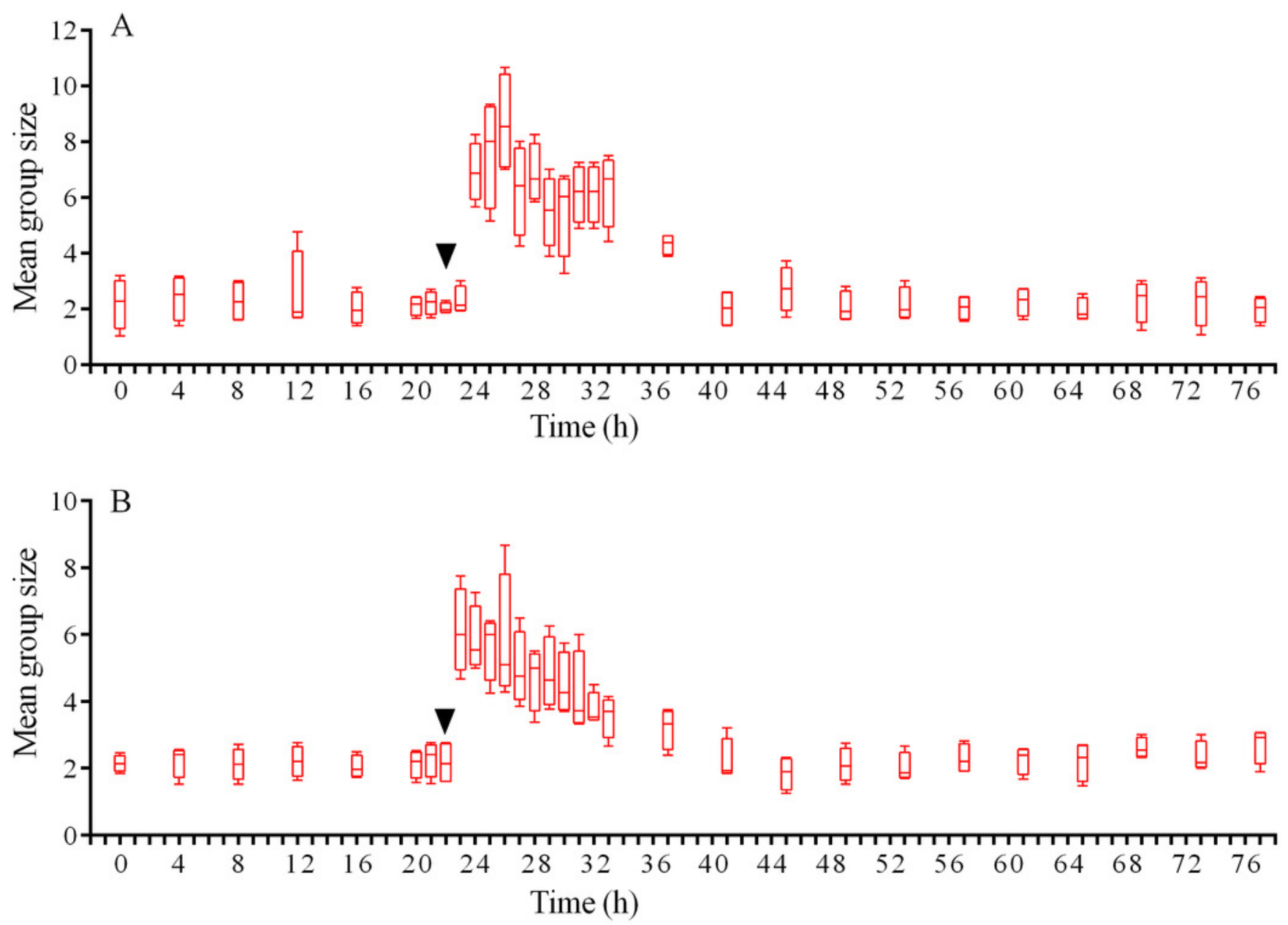
Figure 9

Temporal dynamics of the numbers of sea urchins Strongylocentrotus intermedius in response to simulated predator attack.

(A) Response of S. intermedius to crushed conspecifics. Linear regression is significant $(P<$ 0.0001 , see Table S15 for raw data and statistics). (B) Response of $S$. intermedius to crushed specimens of the sea urchin Mesocentrotus nudus. Linear regression is not significant $(P=$ 0.3485 , see Table S18 for raw data and statistics). The data are presented as median and range. Time of the treatment is indicated by upside down triangle.
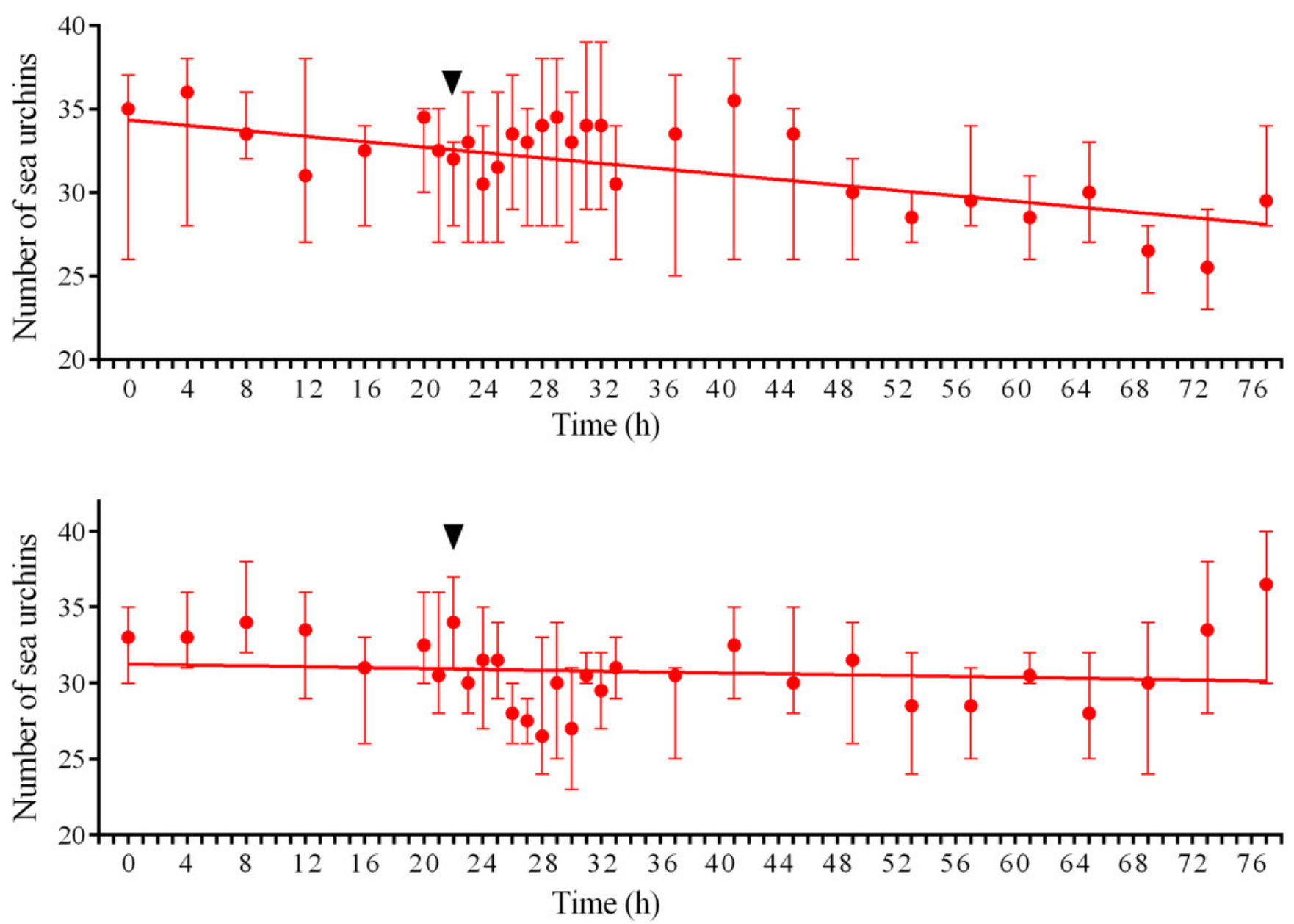
Figure 10

Movement activity of the sea urchins Strongylocentrotus intermedius in response to crushed conspecifics.

Red dotted line denotes sea urchin distance from the site of simulated attack, mean \pm SD ( $n$ $=10)$. SD is shown for every ninth measurement. Red solid line denotes the average step length of sea urchins $(n=10)$. Time of the treatment is indicated by upside down triangle.

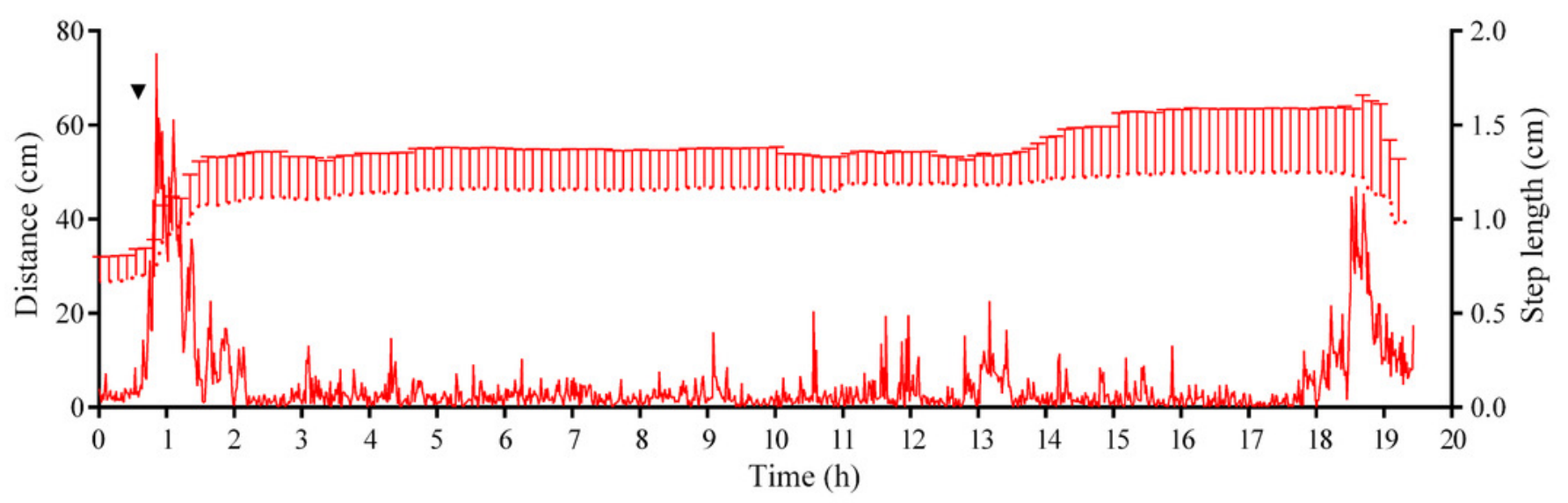




\section{Table 1 (on next page)}

Parameters of movement activity of the sea urchin Mesocentrotus nudus under calm and stormy weather.

Data are presented as Mean \pm SEM $(n=10)$ and the range (in the parentheses) for 240-min interval. 


\begin{tabular}{|c|c|c|c|}
\hline Parameter & Calm weather & Stormy weather & Statistics \\
\hline Number of steps & $\begin{array}{l}110 \pm 12 \\
(50-160)\end{array}$ & $\begin{array}{l}21 \pm 3 \\
(9-35)\end{array}$ & $\begin{array}{l}t_{10}=7,314 ; \mathrm{df}= \\
9.883 ; p<0.0001\end{array}$ \\
\hline Step length, cm & $\begin{array}{l}0.71 \pm 0.08 \\
(0.10-9.54)\end{array}$ & $\begin{array}{l}0.29 \pm 0.02 \\
(0.10-1.34)\end{array}$ & $\begin{array}{l}t_{10}=4.966 ; \mathrm{df}= \\
10.26 ; p=0.0005\end{array}$ \\
\hline Number of moves & $\begin{array}{l}28 \pm 2 \\
(22-35)\end{array}$ & $\begin{array}{l}13 \pm 2 \\
(5-23)\end{array}$ & $\begin{array}{l}t_{10}=5.915 ; \mathrm{df}=18 \\
p<0.0001\end{array}$ \\
\hline Move length, $\mathrm{cm}$ & $\begin{array}{l}2.99 \pm 0.58 \\
(0.10-56.5)\end{array}$ & $\begin{array}{l}0.57 \pm 0.16 \\
(0.10-8.37)\end{array}$ & $\begin{array}{l}\text { Mann-Whitney } \mathrm{U}= \\
5.0 ; p=0.0002\end{array}$ \\
\hline $\begin{array}{l}\text { Entire distance } \\
\text { traversed, } \mathrm{cm}\end{array}$ & $\begin{array}{l}76.90 \pm 11.86 \\
(34.91-146.40)\end{array}$ & $\begin{array}{l}5.87 \pm 0.7 \\
(3.91-9.97)\end{array}$ & $\begin{array}{l}t_{10}=5.98 ; \mathrm{df}= \\
9.063 ; p=0.0002\end{array}$ \\
\hline Number of stops & $\begin{array}{l}28 \pm 2 \\
(22-35)\end{array}$ & $\begin{array}{l}14 \pm 2 \\
(5-24)\end{array}$ & $\begin{array}{l}t_{10}=5.773 ; \mathrm{df}= \\
17.41 ; p<0.0001\end{array}$ \\
\hline Stop duration, min & $\begin{array}{l}4.82 \pm 0.54 \\
(1-43)\end{array}$ & $\begin{array}{l}19.69 \pm 3.02 \\
(1-87)\end{array}$ & $\begin{array}{l}t_{10}=4.845 ; \mathrm{df}= \\
9.566 ; \mathrm{p}=0.0008\end{array}$ \\
\hline $\begin{array}{l}\text { Entire stop duration, } \\
\text { min }\end{array}$ & $\begin{array}{l}130.0 \pm 11.87 \\
(80-190)\end{array}$ & $\begin{array}{l}217.9 \pm 2.73 \\
(205-231)\end{array}$ & $\begin{array}{l}t_{10}=7.219 ; \mathrm{df}= \\
9.95 ; p<0.0001\end{array}$ \\
\hline Speed, $\mathrm{cm} \mathrm{min}{ }^{-1}$ & $\begin{array}{l}0.32 \pm 0.05 \\
(0.15-0.61)\end{array}$ & $\begin{array}{l}0.03 \pm 0.003 \\
(0.02-0.04)\end{array}$ & $\begin{array}{l}t_{10}=6.054 ; \mathrm{df}= \\
9.056 ; p=0.0002\end{array}$ \\
\hline
\end{tabular}




\section{Table 2 (on next page)}

Parameters of movement activity of the sea urchin Strongylocentrotus intermedius under calm and stormy weather.

Data are presented as Mean \pm SEM $(n=10)$ and the range (in the parentheses) for 240 -min interval. 


\begin{tabular}{|c|c|c|c|}
\hline Parameter & Calm weather & Stormy weather & Statistics \\
\hline Number of steps & $\begin{array}{l}160 \pm 10 \\
(110-211)\end{array}$ & $\begin{array}{l}57 \pm 12 \\
(18-141)\end{array}$ & $\begin{array}{l}t_{10}=6.606 ; \mathrm{df}=17.49 \\
p<0.0001\end{array}$ \\
\hline Step length, cm & $\begin{array}{l}0.28 \pm 0.03 \\
(0.10-5.46)\end{array}$ & $\begin{array}{l}0.33 \pm 0.08 \\
(0.10-4.14)\end{array}$ & $\begin{array}{l}\text { Mann-Whitney } \mathrm{U}= \\
33.5 ; p=0.2233\end{array}$ \\
\hline Number of moves & $\begin{array}{l}31 \pm 2 \\
(16-39)\end{array}$ & $\begin{array}{l}26 \pm 3 \\
(13-39)\end{array}$ & $\begin{array}{l}t_{10}=1 ., 147 ; \mathrm{df}=18 ; p \\
=0.2662\end{array}$ \\
\hline Move length, $\mathrm{cm}$ & $\begin{array}{l}1.65 \pm 0.35 \\
(0.10-39.72)\end{array}$ & $\begin{array}{l}0.65 \pm 0.17 \\
(0.10-37.7)\end{array}$ & $\begin{array}{l}\text { Mann-Whitney } \mathrm{U}= \\
13.0 ; p=0.0038\end{array}$ \\
\hline $\begin{array}{l}\text { Entire distance } \\
\text { traversed, } \mathrm{cm}\end{array}$ & $\begin{array}{l}44.28 \pm 5.56 \\
(29.73-88.85)\end{array}$ & $\begin{array}{l}16.10 \pm 4.3 \\
(3.80-45.76)\end{array}$ & $\begin{array}{l}\text { Mann-Whitney } \mathrm{U}= \\
12.0 ; p=0.0029\end{array}$ \\
\hline Number of stops & $\begin{array}{l}31 \pm 2 \\
(18-39)\end{array}$ & $\begin{array}{l}26 \pm 3 \\
(12-38)\end{array}$ & $\begin{array}{l}\mathrm{t}_{10}=1.331 ; \mathrm{df}=15.56 \\
p=0.2023\end{array}$ \\
\hline Stop duration, min & $\begin{array}{l}2.54 \pm 0.26 \\
(1-29)\end{array}$ & $\begin{array}{l}8.63 \pm 1.70 \\
(1-80)\end{array}$ & $\begin{array}{l}t_{10}=3.402 ; \mathrm{df}=9.431 \\
\mathrm{p}=0.0058\end{array}$ \\
\hline $\begin{array}{l}\text { Entire stop duration, } \\
\min \end{array}$ & $\begin{array}{l}80.1 \pm 10.1 \\
(29-130)\end{array}$ & $\begin{array}{l}183.2 \pm 11.97 \\
(99-222)\end{array}$ & $\begin{array}{l}t_{10}=6.592 ; \mathrm{df}=17.49 \\
p<0.0001\end{array}$ \\
\hline Speed, $\mathrm{cm} \mathrm{min}{ }^{-1}$ & $\begin{array}{l}0.19 \pm 0.02 \\
(0.12-0.37)\end{array}$ & $\begin{array}{l}0.07 \pm 0.02 \\
(0.02-0.19)\end{array}$ & $\begin{array}{l}\text { Mann-Whitney } \mathrm{U}= \\
11.0 ; p=0.0019\end{array}$ \\
\hline
\end{tabular}

